\title{
Exchange Rate Pass-Through and Inflation: A Nonlinear Time Series Analysis
}

\author{
by
}

Mototsugu Shintani, Akiko Terada-Hagiwara, and Tomoyoshi Yabu

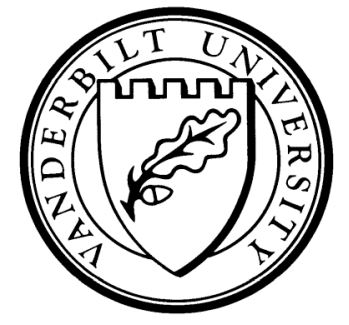

Working Paper No. 09-W20

November 2009

\section{DEPARTMENT OF ECONOMICS \\ VANDERBILT UNIVERSITY \\ NASHVILLE, TN 37235}

www.vanderbilt.edu/econ 


\title{
Exchange Rate Pass-Through and Inflation: A Nonlinear Time Series Analysis*
}

\author{
Mototsugu Shintani†, Akiko Terada-Hagiwara ${ }^{\ddagger}$ and Tomoyoshi Yabu ${ }^{\S}$
}

\begin{abstract}
This paper investigates the relationship between the exchange rate passthrough (ERPT) and inflation by estimating a nonlinear time series model. Using a simple theoretical model of ERPT determination, we show that the dynamics of ERPT can be well-approximated by a class of smooth transition autoregressive (STAR) models with inflation as a transition variable. We employ several U-shaped transition functions in the estimation of the time-varying ERPT to U.S. domestic prices. The estimation result suggests that declines in the ERPT during the 1980s and 1990s are associated with lowered inflation.
\end{abstract}

First Draft: June 2008

This version: November 2009

JEL Classification: C22; E31; F31

Key words and phrases: Import prices; Inflation indexation; Pricing-to-market; Smooth transition autoregressive models; Sticky prices

${ }^{*}$ The authors gratefully acknowledge Mick Devereux, Ippei Fujiwara, Naohisa Hirakata, Kevin Huang, Nobu Kiyotaki, Takushi Kurozumi and seminar and conference participants at the Georgia Institute of Technology, Osaka University, University of Texas at Arlington and the 2009 Far East and South Asia Meeting of the Econometric Society for their helpful comments and discussions. The views expressed in the paper are those of the authors and are not reflective of those of the Asian Development Bank. Address correspondence to: Mototsugu Shintani, Department of Economics, Vanderbilt University, Nashville, TN 37235, USA; e-mail: mototsugu.shintani@vanderbilt.edu.

${ }^{\dagger}$ Department of Economics, Vanderbilt University

${ }^{\ddagger}$ Economics and Research Department, Asian Development Bank

${ }^{\S}$ Faculty of Business \& Commerce, Keio University 


\section{Introduction}

Within the framework of new open economy macroeconomic models, the degree of exchange rate pass-through (ERPT) into domestic prices is one of the key elements determining the size of the spill-over effects of monetary policy. Over the past decade, a number of empirical studies investigated whether the ERPT decreased during the 1980s and the 1990s. ${ }^{1}$ If there is a reduction in the ERPT, it is natural to conjecture the lower and more stable inflations as a possible factor because the timing corresponds, in many countries, to the period of price stability. This view is emphasized by Taylor (2000), who states that "the lower pass-through should not be taken as exogenous to the inflationary environment (p.1390)."

The purpose of this paper is to investigate Taylor's hypothesis on the positive relationship between the ERPT to domestic prices and inflation using nonlinear time series methods. In particular, we employ the class of smooth transition autoregressive (STAR) models to describe the case in which the degree of ERPT is determined by the level of the lagged inflation rate. Most of the previous empirical studies on the positive association between the ERPT and inflation focused on the cross-country evidence, including the analyses by Calvo and Reinhart (2002), Choudhri and Hakura (2006) and Devereux and Yetman (2008). Instead of examining the relationship between the ERPT and average inflation rate across countries, we are interested in examining the role of inflation in the time-varying ERPT using a time series modeling framework.

In the empirical literature on the nonlinear adjustment of real exchange rates, the STAR models have been popularly employed in many analyses, including Michael, Nobay and Peel (1997), Taylor and Peel (2000), Taylor, Peel and Sarno (2001), and Kilian and Taylor (2003), among others. However, this time series approach has rarely been used in studies of ERPT. ${ }^{2}$ We employ several U-shaped transition functions

\footnotetext{
${ }^{1}$ See, for example, Goldberg and Knetter (1997), Otani, Shiratsuka and Shirota (2003), Campa and Goldberg (2005), Sekine (2006) and McCarthy (2007).

${ }^{2}$ One of the few exceptions is Herzberg, Kapetanios and Price's (2003) study of UK import prices. However, they did not find supporting evidence on nonlinearity.
} 
in the STAR model to consider alternative forms of adjustment. Our method is applied to monthly U.S. import and domestic price data in evaluating the timevarying structure of ERPT in the period from 1975 to 2007.

To motivate our nonlinear regression approach, we first construct a simple theoretical model of importing firms where ERPT is predicted to be a nonlinear function of the past inflation rate. The structure of our model is closely related to a model of ERPT developed by Devereux and Yetman (2008). As in Ball, Mankiw and Romer (1988), price setters are allowed to endogenously select the probability of adjusting their price to an optimal level. However, our model differs from that of Devereux and Yetman (2008) in several aspects. First, instead of all firms facing an infinite horizon profit maximization problem à la Calvo (1983), a fraction of firms make finite-period contracts every period as in the Taylor (1980) type staggered contract. Second, each pricing cohort of firms faces the problem of selecting a probability of opting out of a contract inflation indexation rule and setting an optimal price with a payment of a fixed cost. With these modifications, our model predicts that the ERPT depends on the lagged inflation unlike the case of Devereux and Yetman (2008) where ERPT depends on the steady-state inflation level of the economy. Using this model, we show that dynamics of ERPT predicted by the model can be well-approximated by using the STAR formulation. Our estimates of STAR models suggest that the past decline during the 1980s and the 1990s and recent increase in the ERPT to U.S. domestic prices are well-explained by the changes in inflation.

The remainder of the paper is organized as follows. Section 2 describes the theoretical model. Section 3 describes the empirical model, followed by the estimation results. Some concluding remarks are made in Section 4. 


\section{Exchange Rate Pass-Through into Domestic Prices}

\subsection{A Simple Model of Importers}

As in the model of Devereux and Yetman (2008), we consider a continuum of importing firms, each of which imports a differentiated intermediate good from abroad and sells it in the domestic market as a monopolistic competitor. A representative domestic final good producer purchases all the imported intermediate goods and combines them to produce a final output without controlling its output price. To describe the price setting behavior of importing firms, we modify Taylor's (1980) staggered pricing model in which contracts between the importers and the final good producer are $N(\geq 2)$ periods long, and a constant fraction $1 / N$ of all importing firms determine their contracts in any given time period. A firm that determines the pricing contract at time $t-j$ (for $j=0,1, \ldots, N-1$ ) and imports a good $i$ at time $t$ is facing a demand given by

$$
C_{t}(i, t-j)=\left(\frac{P_{t}(i, t-j)}{P_{t}(t-j)}\right)^{-\theta} C_{t}(t-j)
$$

where $\theta>1$ is a constant elasticity of substitution, $P_{t}(i, t-j)$ is the price of a good $i$ imported by a firm with a contract beginning in period $t-j, P_{t}(t-j)=$

$\left(\int_{0}^{1} P_{t}(i, t-j)^{1-\theta} d i\right)^{1 /(1-\theta)}$ is the price index for the composite intermediate good sold by importing firms whose contracts begin in period $t-j$, and $C_{t}(t-j)$ is the demand for the corresponding composite good. All the differentiated intermediate goods, $i \in[0,1]$, are imported at the same foreign currency price, $P_{t}^{*}$, which is beyond the control of importers. The importer's profit, in term of the domestic currency, at time $t$ is given by

$$
\Pi_{t}(i, t-j)=P_{t}(i, t-j) C_{t}(i, t-j)-(1+\tau) S_{t} P_{t}^{*} C_{t}(i, t-j)
$$

where $S_{t}$ is the nominal exchange rate and $\tau$ is the iceberg transportation cost the importer must bear. The importer's desired price which maximizes the profit under 
flexible price economy is

$$
\widehat{P}_{t}(i, t-j)=\frac{\theta}{\theta-1}(1+\tau) S_{t} P_{t}^{*}
$$

where $\theta /(\theta-1)$ and $(1+\tau) S_{t} P_{t}^{*}$ represent the mark-up and marginal cost, respectively. By taking a log of the desired price, which is same across all the importing firms $\left(\widehat{P}_{t}=\right.$ $\left.\widehat{P}_{t}(i, t-j)\right)$, we have $\widehat{p}_{t}=s_{t}+p_{t}^{*}+\mu$ where $s_{t}=\ln S_{t}$ and $\mu=\ln (\theta /(\theta-1))+\ln (1+\tau){ }^{3}$ In this paper, both $s_{t}$ and $p_{t}^{*}$ are assumed to follow (possibly mutually correlated) random walk processes with a variance of the sum of each increment, $\Delta\left(s_{t}+p_{t}^{*}\right)$, given by $\sigma^{2}$. We further assume that the elasticity of substitution among composite intermediate goods sold by each fraction $1 / N$ of all importing firms is one, and thus aggregate price index at time $t$ (in $\log$ ) is $p_{t}=N^{-1} \sum_{j=0}^{N-1} p_{t}(t-j)$ where $p_{t}(t-j)=\ln P_{t}(t-j)$. Our interest is the effect of marginal cost changes $\Delta\left(s_{t}+p_{t}^{*}\right)$ on the aggregate inflation rate given by $\pi_{t}=p_{t}-p_{t-1} \cdot{ }^{4}$

In reality, contracts written for fixed periods can, in special circumstances, be re-negotiated. Ball and Mankiw (1994) and Devereux and Siu (2007) add to the two-period Taylor model the possibility that in the second half of their contracts, firms can choose to opt out and reset the price by paying a fixed (menu) cost. We introduce a similar pricing scheme by dividing the total of $N$ periods into two subperiods, with the first subperiod $N_{1}(\geq 1)$, during which the firms follow the contract pricing rule, and the second subperiod $N_{2}\left(=N-N_{1}\right)$ after opting out of the contract. During the contract period, firms are assumed to fully index their prices to aggregate inflation of the initial period. ${ }^{5}$ In Devereux and Siu (2007), each firm observes its fix cost, which is assumed to be i.i.d. across firms, after setting its (two-period) contract

\footnotetext{
${ }^{3}$ In our empirical part of the analysis, we examine not only the case with constant $\mu$ but also the case where $\mu$ varies in response to demand shocks.

${ }^{4}$ As in Devereux and Yetman (2008), a full pass-through of nominal exchange rate changes into the import prices is implicitly assumed here. A recent empirical study by Goldberg and Campa (2008) also investigates the pass-through into the domestic prices rather than import prices using a model of the production sector with imported inputs.

${ }^{5}$ Note that prices are indexed to inflation of the initial period only, instead of following the periodby-period lagged inflation indexation rule of Christiano, Eichenbaum and Evans (2005). While the latter pricing scheme can be also introduced in our model, the former assumption greatly simplifies the analysis.
} 
price. Consequently, the pricing in the second period becomes state-dependent with all firms facing the same probability of opting out in the second period. ${ }^{6}$ We also let firms make their decision in a sequential manner by assuming that the aggregate inflation is not observed by individual firms at the time of the contract. Since the marginal cost follows a random walk and the probability of opting out is not known in the beginning, all the firms entering into new contracts at time $t$ set their price at $\widehat{p}_{t}$. The firm that decides to opt out at time $t+N_{1}$ also chooses a flexible price at each period during the second subperiod, with its entire price path given by $\left\{\widehat{p}_{t}, \widehat{p}_{t}+\pi_{t}, \ldots, \widehat{p}_{t}+\left(N_{1}-1\right) \pi_{t}, \widehat{p}_{t+N_{1}}, \ldots, \widehat{p}_{t+(N-1)}\right\}$.

In this paper, we do not formally derive the state-dependent pricing solution. Instead, we follow Ball, Mankiw and Romer (1988), Romer (1990) and Devereux and Yetman $(2002,2008)$, among others, and re-formulate the firm's optimization behavior so that the probability of (not) changing its price to the desired price level is endogenously determined. Let $\kappa^{(t)}$ be the probability that a firm under contract in the current period will maintain the contract price in the next period. Here, a superscript $t$ in parenthesis signifies that this probability applies to all the firms entering into new contracts at time $t$, but not to other pricing cohorts. After setting the new contract price at $t$, the firms observe the aggregate inflation $\pi_{t}$ and choose $\kappa^{(t)}$ to maximize their profit. As in Walsh (2003), we can rewrite the intertemporal profit maximization condition using the expected squared deviation of the actual price from the desired price in each period. In our case, an optimal value of $\kappa^{(t)}$ is selected by minimizing the expected loss function

$$
L_{t}=E_{t}\left[\sum_{j=1}^{N-1}\left(\beta \kappa^{(t)}\right)^{j}\left(\widehat{p}_{t}+j \pi_{t}-\widehat{p}_{t+j}\right)^{2}\right]+\frac{1-\kappa^{(t)}}{\kappa^{(t)}} \sum_{j=1}^{N-1}\left(\beta \kappa^{(t)}\right)^{j}\left(\sum_{\ell=1}^{N-j} \beta^{\ell-1}\right) F
$$

where $\beta$ is a discount factor and $F$ is a fixed cost. The above function implies that the loss is an increasing function of the squared inflation rate, $\pi_{t}^{2}$. As the inflation rate

\footnotetext{
${ }^{6}$ For this reason, Devereux and Siu (2007) refer it to the hybrid time- and state-dependent pricing rule.
} 
rises (relative to the size of the fixed cost), the firm can minimize the loss by avoiding the inflation indexation. This strategy leads to a lower $\kappa^{(t)}$ or a shorter average length of $N_{1}$ given by $\sum_{\ell=1}^{N-1}\left(\kappa^{(t)}\right)^{\ell}+1$. In an extreme case of a high inflation, $\kappa^{(t)}=0$ (or $\left.N_{1}=1\right)$ is selected with a pricing path given by $\left\{\widehat{p}_{t}, \widehat{p}_{t+1}, \ldots, \widehat{p}_{t+(N-1)}\right\}$. In the other extreme case of a large fixed cost, $\kappa^{(t)}=1$ (or $N_{1}=N$ ) is selected with a pricing path given by $\left\{\widehat{p}_{t}, \widehat{p}_{t}+\pi_{t}, \widehat{p}_{t}+2 \pi_{t}, \ldots, \widehat{p}_{t}+(N-1) \pi_{t}\right\}$.

While the formulation of our model closely follows that of Devereux and Yetman (2008), there are at least two notable differences between the pricing schemes of two models. First, importers in Devereux and Yetman (2008) face the problem of choosing the probability $\kappa$ of making no price adjustment to maximize the profit over the infinite horizon under the framework of a standard Calvo (1983) type sticky price model. In contrast, our importers optimize over the finite contract period in the Taylor (1980) type staggered pricing model by choosing the probability $\kappa^{(t)}$ of maintaining the contract pricing rule. Since the optimization problem is resolved by importers entering into new contracts every period, the selected probability $\kappa^{(t)}$ generally differs across pricing cohorts, unlike $\kappa$, which is common for all the firms in the economy. ${ }^{7}$ Second, our importers adapt an inflation indexation rule during the contract period, rather than fix their price at a constant level. Under such a contract, price deviations from the desired price level depend on the aggregate inflation rate of the initial contract period. Thus, the optimal level of the probability $\kappa^{(t)}$ becomes a function of inflation. Because of this mechanism, our model predicts that the ERPT depends on the lagged inflation unlike the case of Devereux and Yetman (2008) where ERPT depends on the steady-state inflation level of the economy. In the next subsection, we derive the functional form of the ERPT, and show its dependence on the multiple pricing cohorts in the economy. ${ }^{8}$

\footnotetext{
${ }^{7}$ It should also be noted that $1-\kappa$ in the Calvo type model is an unconditional probability of the firm setting the optimal price in each period, but $1-\kappa^{(t)}$ in our model is a conditional probability of adapting the optimal pricing rule given that the firm has been following the contract pricing rule.

${ }^{8}$ In addition to the aggregate price level, the model also predicts the aggregate output level. We only consider the former implication since the main focus of our analysis is the ERPT.
} 


\subsection{Exchange Rate Pass-Through as A Function of Inflation}

\section{(A) Two-period contract case}

Let us first consider the simplest case where each contract is written for two periods as in Ball and Mankiw (1994) and Devereux and Siu (2007). The loss function (1) with $N=2$ is given by

$$
\begin{aligned}
L_{t} & =E_{t}\left[\beta \kappa^{(t)}\left(\widehat{p}_{t}+\pi_{t}-\widehat{p}_{t+1}\right)^{2}\right]+\beta\left(1-\kappa^{(t)}\right) F \\
& =\beta F-\beta\left(F-\sigma^{2}-\pi_{t}^{2}\right) \kappa^{(t)} .
\end{aligned}
$$

Here we exclude the possibility of $F<\sigma^{2}$, since the loss is always minimized by setting $\kappa^{(t)}=0$ in such a case. When $F \geq \sigma^{2}$, the firm selects $\kappa^{(t)}=1$ if $\pi_{t}^{2} \leq F-\sigma^{2}$

and $\kappa^{(t)}=0$ if $\pi_{t}^{2}>F-\sigma^{2}$. Thus, for the given values of $F$ and $\sigma^{2}, \kappa^{(t)}$ is simply a function of $\pi_{t}$. Using the same argument, for any firms entering into contracts at time $t-j, \kappa^{(t-j)}$ is a function of $\pi_{t-j}$ given by

$$
\kappa\left(\pi_{t-j}\right)=\left\{\begin{array}{ccc}
1 & \text { if } & -\sqrt{F-\sigma^{2}} \leq \pi_{t-j} \leq \sqrt{F-\sigma^{2}} \\
0 & \text { otherwise. }
\end{array}\right.
$$

Using the definition of the aggregate price index, we have

$$
\begin{aligned}
p_{t} & =\frac{1}{2}\left(p_{t}(t)+p_{t}(t-1)\right) \\
& =\left(s_{t}+p_{t}^{*}+\mu\right)-\frac{\kappa\left(\pi_{t-1}\right)}{2} \Delta\left(s_{t}+p_{t}^{*}\right)+\frac{\kappa\left(\pi_{t-1}\right)}{2} \pi_{t-1}
\end{aligned}
$$

since the firms with new contracts set their price $p_{t}(t)$ at the desired price, $\widehat{p}_{t}=$ $s_{t}+p_{t}^{*}+\mu$, and the firms with contracts made in the previous period set their price $p_{t}(t-1)$ at $\left(1-\kappa\left(\pi_{t-1}\right)\right) \widehat{p}_{t}+\kappa\left(\pi_{t-1}\right)\left(\widehat{p}_{t-1}+\pi_{t-1}\right)$. The inflation dynamics is written as

$\pi_{t}=\left(1-\frac{\kappa\left(\pi_{t-1}\right)}{2}\right) \Delta\left(s_{t}+p_{t}^{*}\right)+\frac{\kappa\left(\pi_{t-2}\right)}{2} \Delta\left(s_{t-1}+p_{t-1}^{*}\right)+\frac{\kappa\left(\pi_{t-1}\right)}{2} \pi_{t-1}-\frac{\kappa\left(\pi_{t-2}\right)}{2} \pi_{t-2}$.

We follow Devereux and Yetman (2008) among others and consider the (short-run) ERPT in terms of the first derivative of $\pi_{t}$ with respect to $\Delta\left(s_{t}+p_{t}^{*}\right)$, or

$$
E R P T=1-\frac{\kappa\left(\pi_{t-1}\right)}{2}
$$


which depends on the lagged inflation, $\pi_{t-1} \cdot{ }^{9}$ When $-\sqrt{F-\sigma^{2}} \leq \pi_{t-1} \leq \sqrt{F-\sigma^{2}}$, $\kappa\left(\pi_{t-1}\right)$ takes a value of one and the ERPT becomes 0.5 . On the other hand, when $\left|\pi_{t-1}\right|>\sqrt{F-\sigma^{2}}$, the model predicts a full ERPT. In summary, the model with $N=2$ implies the abrupt transition of the degree of the ERPT depending on the relative size of a threshold variable $\left|\pi_{t-1}\right|$ and a threshold value $\sqrt{F-\sigma^{2}}$ as depicted in Figure 1. The shape of the step function in the figure suggests the possibility of approximating the ERPT by a variation of a threshold autoregressive model (TAR), sometimes referred to as the three-regime TAR model or the band TAR model.

\section{(B) Three-period contract case}

When $N=3$, the loss function (1) becomes a quadratic function of $\kappa^{(t)}$ given by

$$
\begin{aligned}
L_{t}= & E_{t}\left[\beta \kappa^{(t)}\left(\widehat{p}_{t}+\pi_{t}-\widehat{p}_{t+1}\right)^{2}+\left(\beta \kappa^{(t)}\right)^{2}\left(\widehat{p}_{t}+2 \pi_{t}-\widehat{p}_{t+2}\right)^{2}\right] \\
& +\beta\left(1-\kappa^{(t)}\right)(1+\beta) F+\beta^{2} \kappa^{(t)}\left(1-\kappa^{(t)}\right) F \\
= & \beta(1+\beta) F-\beta\left(F-\sigma^{2}-\pi_{t}^{2}\right) \kappa^{(t)}-\beta^{2}\left(F-2 \sigma^{2}-4 \pi_{t}^{2}\right)\left(\kappa^{(t)}\right)^{2} .
\end{aligned}
$$

The first order condition yields the optimal $\kappa^{(t)}$ given by

$$
\kappa\left(\pi_{t}\right)=\frac{-\left(F-\sigma^{2}-\pi_{t}^{2}\right)}{2 \beta\left(F-2 \sigma^{2}-4 \pi_{t}^{2}\right)}
$$

provided $F-\sigma^{2}-\pi_{t}^{2}>0$ and $\left(F-\sigma^{2}-\pi_{t}^{2}\right)+2 \beta\left(F-2 \sigma^{2}-4 \pi_{t}^{2}\right)<0$. In this case, $\kappa^{(t)}$ is a smooth function of the inflation rate $\pi_{t}$. Otherwise, $\kappa^{(t)}$ becomes a corner solution taking a value of either 0 or $1 .{ }^{10}$ The aggregate price is given by

$$
\begin{aligned}
p_{t}= & \frac{1}{3}\left(p_{t}(t)+p_{t}(t-1)+p_{t}(t-2)\right) \\
= & \left(s_{t}+p_{t}^{*}\right)-\frac{\kappa\left(\pi_{t-1}\right)+\kappa\left(\pi_{t-2}\right)^{2}}{3} \Delta\left(s_{t}+p_{t}^{*}\right)-\frac{\kappa\left(\pi_{t-2}\right)^{2}}{3} \Delta\left(s_{t-1}+p_{t-1}^{*}\right) \\
& +\frac{\kappa\left(\pi_{t-1}\right)}{3} \pi_{t-1}+\frac{2 \kappa\left(\pi_{t-2}\right)^{2}}{3} \pi_{t-2}
\end{aligned}
$$

where the second equality follows from $p_{t}(t-1)=\left(1-\kappa\left(\pi_{t-1}\right)\right) \widehat{p}_{t}+\kappa\left(\pi_{t-1}\right)\left(\widehat{p}_{t-1}+\pi_{t-1}\right)$ and $p_{t}(t-2)=\left(1-\kappa\left(\pi_{t-2}\right)^{2}\right) \widehat{p}_{t}+\kappa\left(\pi_{t-2}\right)^{2}\left(\widehat{p}_{t-2}+2 \pi_{t-2}\right)$. The inflation dynamics

\footnotetext{
${ }^{9}$ Because of the random walk assumption in our model, this ERPT also corresponds to the ERPT defined by the first derivative of $\pi_{t}$ with respect to $\Delta s_{t}$.

${ }^{10}$ If $F-\sigma^{2}-\pi_{t}^{2}>0$ and $\left(F-\sigma^{2}-\pi_{t}^{2}\right)+2 \beta\left(F-2 \sigma^{2}-4 \pi_{t}^{2}\right) \geq 0$, then $\kappa\left(\pi_{t}\right)=1$. If $F-\sigma^{2}-\pi_{t}^{2} \leq 0$, then $\kappa\left(\pi_{t}\right)=0$.
} 
are given by

$$
\begin{aligned}
\pi_{t}= & \left(1-\frac{\kappa\left(\pi_{t-1}\right)+\kappa\left(\pi_{t-2}\right)^{2}}{3}\right) \Delta\left(s_{t}+p_{t}^{*}\right) \\
& -\frac{1}{3}\left(\kappa\left(\pi_{t-2}\right)^{2}-\kappa\left(\pi_{t-2}\right)-\kappa\left(\pi_{t-3}\right)^{2}\right) \Delta\left(s_{t-1}+p_{t-1}^{*}\right)+\frac{\kappa\left(\pi_{t-3}\right)^{2}}{3} \Delta\left(s_{t-2}+p_{t-2}^{*}\right) \\
& +\frac{\kappa\left(\pi_{t-1}\right)}{3} \pi_{t-1}+\frac{1}{3}\left(2 \kappa\left(\pi_{t-2}\right)^{2}-\kappa\left(\pi_{t-2}\right)\right) \pi_{t-2}-\frac{2 \kappa\left(\pi_{t-3}\right)^{2}}{3} \pi_{t-3} .
\end{aligned}
$$

The ERPT is given by

$$
E R P T=1-\frac{\kappa\left(\pi_{t-1}\right)+\kappa\left(\pi_{t-2}\right)^{2}}{3}
$$

which now depends on $\pi_{t-1}$ and $\pi_{t-2}$. The ERPT takes a minimum value of $1 / 3$ when both $\kappa\left(\pi_{t-1}\right)$ and $\kappa\left(\pi_{t-2}\right)$ are one. In the other extreme case, a full ERPT can be obtained when both $\kappa\left(\pi_{t-1}\right)$ and $\kappa\left(\pi_{t-2}\right)$ are zero. Figure 2 shows the relationship between the inflation rate (imposing $\pi_{t-1}=\pi_{t-2}$ ) and the ERPT when $\kappa\left(\pi_{t-1}\right)$ and $\kappa\left(\pi_{t-2}\right)$ take some values between zero and one. The smooth nonlinear relationship between inflation and the ERPT resembles the adjustment dynamics described by the class of STAR model with lagged inflation rates used as transition variables. In particular, the symmetric relationship around zero suggests a symmetric U-shaped transition function such as an exponential function.

\section{(C) N-period contract case}

A similar argument yields the ERPT for any $N$ given by

$$
E R P T=1-\frac{\sum_{j=1}^{N-1} \kappa\left(\pi_{t-j}\right)^{j}}{N}
$$

where $\kappa\left(\pi_{t-j}\right)$ is a nonlinear function of $\pi_{t-j}$. The second term $N^{-1} \sum_{j=1}^{N-1} \kappa\left(\pi_{t-j}\right)^{j}$ represents the fraction of firms adapting the indexation rule and the ERPT can now vary from $1 / N$ to 1 . Again, the ERPT is a smooth nonlinear function of inflation, with its dynamics possibly approximated by a U-shaped transition function with a set of lagged inflation rates used as transition variables. The current inflation becomes a function of $\pi_{t-j}$ for $j=1, \ldots, N$ and $\Delta\left(s_{t-j}+p_{t-j}^{*}\right)$ for $j=0, \ldots, N-1$. 


\section{Nonlinear Time Series Analysis}

\subsection{STAR Models}

To seek for a suitable specification of the STAR model used in the empirical analysis, let us summarize the predictions of the theoretical model introduced in the previous section. First, higher inflation (in absolute value) results in a higher degree of the ERPT. Second, the ERPT is a symmetric function of the past inflation rates around zero. Finally, in general, dynamics of the ERPT can be described as a smooth rather than an abrupt transition using past inflation rates as transition variables possibly with multiple lags. The only exception is a special case of twoperiod contract that predicts a discrete transition typically assumed in the TAR model.

To capture these features in a parsimonious, parametric model, we primarily employ the exponential STAR (ESTAR) model with an exponential function used as a symmetric U-shaped transition function. It is a popularly used STAR model originally proposed by Haggan and Ozaki (1981) and later generalized by Granger and Teräsvirta (1993) and Teräsvirta (1994). Since our objective is to determine the relationship between $\pi_{t}$ and $\Delta\left(s_{t}+p_{t}^{*}\right)$, we estimate a bivariate version of the ESTAR model specified as

$$
\begin{aligned}
\pi_{t}= & \phi_{0}+\sum_{j=1}^{N} \phi_{1, j} \pi_{t-j}+\sum_{j=0}^{N-1} \phi_{2, j} \Delta\left(s_{t-j}+p_{t-j}^{*}\right) \\
& +\left(\sum_{j=1}^{N} \phi_{3, j} \pi_{t-j}+\sum_{j=0}^{N-1} \phi_{4, j} \Delta\left(s_{t-j}+p_{t-j}^{*}\right)\right) G\left(z_{t} ; \gamma\right)+\varepsilon_{t},
\end{aligned}
$$

where $\varepsilon_{t} \sim$ i.i.d. $\left(0, \sigma_{\varepsilon}^{2}\right)$ and an exponential transition function given by

$$
G\left(z_{t} ; \gamma\right)=1-\exp \left\{-\gamma z_{t}^{2}\right\}
$$

where $\gamma(>0)$ is a parameter defining the smoothness of the transition, and $z_{t}$ is a transition variable. While our theoretical model suggests multiple transition variables, here we consider a parsimonious specification and use a moving average of 
the past inflation rates as a single transition variable, $z_{t}=d^{-1} \sum_{j=1}^{d} \pi_{t-j}{ }^{11}$ In this ESTAR framework, our interest is to obtain the time-varying ERPT defined as

$$
E R P T=\phi_{2,0}+\phi_{4,0} G\left(z_{t} ; \gamma\right)
$$

We impose a restriction $0 \leq \phi_{2,0} \leq 1$ and $\phi_{2,0}+\phi_{4,0}=1$ so that the ERPT falls in the range of $[0,1]$.

In addition to the ESTAR model, our primary model in the analysis, we also consider another STAR model based on a different U-shaped transition function constructed from a combination of two logistic functions. This variant of a logistic STAR (LSTAR) model has been considered in Granger and Teräsvirta (1993) and Bec, Ben Salem, and Carrasco (2004) and sometimes referred to as the three regime LSTAR model. Here we simply call the model a dual (or double) LSTAR (DLSTAR) model to emphasize the presence of two logistic functions. ${ }^{12}$ The transition function in the DLSTAR model is given by

$$
G\left(z_{t} ; \gamma_{1}, \gamma_{2}, c\right)=\left(1+\exp \left\{-\gamma_{1}\left(z_{t}-c_{1}\right)\right\}\right)^{-1}+\left(1+\exp \left\{\gamma_{2}\left(z_{t}+c_{2}\right)\right\}\right)^{-1}
$$

where $\gamma_{1}, \gamma_{2}(>0)$ are parameters defining the smoothness of the transition in the positive and negative regions respectively, and $c_{1}, c_{2}(>0)$ are location parameters. The definition of all other variables and parameters remains the same as in the ESTAR model. The function of our interest, the ERPT, is similarly computed as

$$
E R P T=\phi_{2,0}+\phi_{4,0} G\left(z_{t} ; \gamma_{1}, \gamma_{2}, c_{1}, c_{2}\right)
$$

The reason for considering this alternative specification of the transition function is two-fold. First, as pointed out by van Dijk, Teräsvirta, and Franses (2002), the transition function in the ESTAR model collapses to a constant when $\gamma$ approaches

\footnotetext{
${ }^{11}$ As in Kilian and Taylor (2003), we can also employ the transition variable, $z_{t}=\sqrt{d^{-1} \sum_{j=1}^{d} \pi_{t-j}^{2}}$, which yields a similar parsimonious specification. The main result turns out to be unaffected even if our transition variable is replaced by this alternative one.

${ }^{12}$ We use this terminology since the model differs from the multple regime STAR models defined in van Dijk, Teräsvirta, and Franses (2002).
} 
infinity. Thus the model does not nest the TAR model with an abrupt transition as predicted by the theory when there are only two pricing cohorts of firms in the economy. In contrast, the DLSTAR model includes the TAR model by letting $\gamma_{1}$, $\gamma_{2}$ tend to infinity. Second, and more importantly, the model can incorporate both symmetric $\left(\gamma_{1}=\gamma_{2}\right.$ and $\left.c_{1}=c_{2}\right)$ and asymmetric $\left(\gamma_{1} \neq \gamma_{2}\right.$ and $\left.c_{1} \neq c_{2}\right)$ adjustments between the positive and negative regions. Therefore, we can investigate the case beyond our simple model that predicts a symmetric relationship between the ERPT and the inflation rate. In the following section, we employ the symmetric DLSTAR model as one of the baseline specifications, but later consider the case of an asymmetric adjustment.

\subsection{Main Empirical Results}

All the data we use in the STAR estimation is the taken from International Financial Statistics (IFS) of the International Monetary Fund. First, the main regressor in the ERPT regression is the monthly log changes in nominal exchange rate and import price in foreign currency. Since the U.S. import price index constructed by Bureau of Labor Statistics is based on U.S. dollar prices paid by the U.S. importer, $\Delta\left(s_{t}+p_{t}^{*}\right)$ is simply computed as $100 \times\left(\ln I M P_{t}-\ln I M P_{t-1}\right)$ where $I M P_{t}$ is the import price after making a seasonal adjustment using X-12-ARIMA procedure. The prices are generally either "free on board (f.o.b.)" foreign port or "cost, insurance, and freight (c.i.f.)" U.S. port transaction prices, depending on the practices of the individual industry. In either case, under our assumption of a constant iceberg transaction cost (proportional to import price in domestic currency), the same formula can be used to compute the monthly log changes in the prices of imported goods, excluding the cost of transaction. Second, for the inflation used for the dependent and transition variables, we employ the producer price index rather than the consumer price index since

the domestic price in our model is the price at which the final good producer sells its 
product. ${ }^{13}$ The monthly $\log$ inflation $\pi_{t}$ is computed as $100 \times\left(\ln P P I_{t}-\ln P P I_{t-1}\right)$ where $P P I_{t}$ is the seasonally adjusted U.S. producer price index. As shown in Figure 3, our sample period from January 1975 to December 2007 covers the high inflation episodes in the late 1970s and the relatively stable inflation environment beginning in the 1980s, as well as the recent resurgence of a hike in the oil prices.

Before estimating the ESTAR model, we first conduct the LM tests of linearity against the ESTAR alternative developed by Saikkonen and Luukkonen (1988). See Appendix A.1 for the details of this linearity test. We will denote the original LM test by $L M_{1}$ and its heteroskedasticity-robust variant suggested by Granger and Teräsvirta (1993) by $L M_{1}^{*}$. The results using $N=6$ and $d$ between 1 and 6 are reported in the upper half of Table 1. Both tests strongly suggest the presence of nonlinearity in inflation dynamics for all values of $d$.

Second, we search for the length of moving average $d$ in the transition variable $z_{t}$ that best fits the specification. We fix the lag length $N=6$ and search for the value of $d$ between 1 and 6 that minimizes the residual sum of squares from the nonlinear least squares regression of (4). This search procedure leads to the choice of $d=3$.

Third, we adopt a general-to-specific approach, as suggested by van Dijk, Teräsvirta, and Franses (2002), in arriving at the final specification. Starting with a model with $N=6$, we sequentially remove the lagged variables for which the $t$ statistic of the corresponding parameter is less than 1.0 in absolute value. The resulting final specification and the estimates for the ESTAR model are provided in the panel A of Table 2. The estimate of the scaling parameter $\gamma$ is expressed in terms of the transition variable $z_{t}=3^{-1} \sum_{j=1}^{3} \pi_{t-j}$ divided by its sample standard deviation 0.477 . The model performs well in terms of the goodness of fit and statistically significant coefficient estimates. Furthermore, there is no evidence of remaining autocorrelations in residuals.

\footnotetext{
${ }^{13}$ There are other studies that also reports ERPT to producer price index. See, for example, Choudhri, Faruqee and Hakura (2005) and McCarthy (2007).
} 
Based on the parameter estimates, we show the implied ERPT $\widehat{\phi}_{2,0}+\widehat{\phi}_{4,0} G\left(z_{t} ; \widehat{\gamma}\right)$ in Figure 4 against the transition variable $z_{t}=3^{-1} \sum_{j=1}^{3} \pi_{t-j}$ (the circles denoting the actual data points). The plot suggests that the degree of ERPT becomes largest when the transition variable, namely the average inflation rate, becomes above 2 percent in absolute term. Figure 5 shows the time-varying ERPT implied by the estimates over the sample period. The ERPT takes the values between 0.34 and 0.85. The plots illustrate three distinct high ERPT episodes. The first high ERPT period corresponds to the second oil shock in the 1970s. During the 1980s and 1990s, the ERPT is relatively stable except for the early 1990s when the producer price index is relatively volatile. During the decade beginning in 2000, the ERPT becomes high again due to the increased volatility of inflation.

For the symmetric version of the DLSTAR model, two LM tests $\left(L M_{2}\right.$ and $\left.L M_{2}^{*}\right)$ reported in Table 1 reject the linearity hypothesis for all the lag delay parameters. ${ }^{14}$ The panel B of Table 2 shows the estimation result of the symmetric DLSTAR model. Using a procedure similar to the one employed for the ESTAR model estimation, we select $d=1$ for the transition variable and reported lags for the regressors. Again, the estimate of the scaling parameter $\gamma\left(=\gamma_{1}=\gamma_{2}\right)$ is expressed in terms of a normalized transition variable. As shown in Figure 6, the shape of the implied ERPT $\widehat{\phi}_{2,0}+\widehat{\phi}_{4,0} G\left(z_{t} ; \widehat{\gamma}, \widehat{c}\right)$ as a function of the transition variable $z_{t}=\pi_{t-1}$ somewhat resembles the shape of the transition function of TAR model predicted by the twoperiod contract case (Figure 1). In addition to a threshold-model-like shape of the transition function, a larger variation of the transition variable, due to one lagged inflation $(d=1)$ instead of its smoothed average $(d>1)$, results in many data points near full ERPT. Because of these features, the time series variation of ERPT based on the DLSTAR model shown in Figure 7 becomes larger than the one based on the ESTAR model shown in Figure 5.

\footnotetext{
${ }^{14}$ Since the test of linearity against DLSTAR models is not available in the literature, we provide the details of the construction of this test in Appendix A.1.
} 


\subsection{Further Analyses}

\section{(A) Introduction of asymmetric adjustment}

We now turn to the estimation of the asymmetric version of the DLSTAR model to incorporate the possibility of asymmetric adjustment. The statistics $L M_{3}$ and $L M_{3}^{*}$ reported in Table 1 suggest the evidence against linearity in favor of the asymmetric DLSTAR specification. ${ }^{15}$ Minimizing the sum of the squared residuals yields the choice of $d=1$. The final specification of the model with parameter estimates is presented in Table 3. Again, the estimates of the scaling parameters $\gamma_{1}$ and $\gamma_{2}$ are expressed in terms of the normalized transition variable.

Figure 8 plots the implied ERPT $\widehat{\phi}_{2,0}+\widehat{\phi}_{4,0} G\left(z_{t} ; \widehat{\gamma}_{1}, \widehat{\gamma}_{2}, \widehat{c}_{1}, \widehat{c}_{2}\right)$ against the transition variable $z_{t}=\pi_{t-1}$ when we allow for the asymmetric adjustment. In terms of the shape of the transition function, the asymmetric DLSTAR specification yields a very similar result compared to the symmetric DLSTAR specification. However, because the estimate of $\gamma_{2}$ is much larger than that of $\gamma_{1}$, the transition is much faster in the negative region. Figure 9 shows the time series plots of the ERPT implied by the asymmetric DLSTAR model estimates over the sample period. The ERPT varies between the values of 0.34 and 1.00 and its path is very similar to the one implied by the symmetric DLSTAR model.

\section{(B) Specification test for the choice of the transition function}

Table 4 reports the results of the specification test to select an appropriate transition function among the ESTAR, the symmetric DLSTAR and the asymmetric DLSTAR models. The details of the test statistics are provided in Appendix A.2. In some cases, the null hypothesis of the ESTAR model against the asymmetric DLSTAR model cannot be rejected (see $L M_{5}$ with $d$ greater than 3 ). On the other hand, the evidence suggests some possibility of rejection of the symmetric DLSTAR model in favor of the asymmetric DLSTAR $\left(L M_{4}\right)$ and the ESTAR specifications $\left(L M_{6}\right)$.

\footnotetext{
${ }^{15}$ See Appendix A.1 for these tests in detail.
} 
While the evidence is somewhat mixed, the ESTAR and asymmetric DLSTAR specifications may be slightly better than the symmetric DLSTAR specification.

\section{(C) Introduction of demand shocks}

Following Campa and Goldberg (2005), we also include the real output measure as an additional variable that represents the demand shock component of the domestic market. We use the index of industrial production normalized by the consumer price index (CPI) as a proxy for the change in demand. A modified ESTAR model we estimate is

$\pi_{t}=F\left(\Delta\left(s_{t}+p_{t}^{*}\right), \ldots, \Delta\left(s_{t-N+1}+p_{t-N+1}^{*}\right), \pi_{t-1}, \ldots, \pi_{t-N}, z_{t} ; \phi, \gamma\right)+\sum_{j=0}^{p} a_{j} \Delta i i p_{t-j}+\varepsilon_{t}$

where $F\left(\Delta\left(s_{t}+p_{t}^{*}\right), \ldots, \Delta\left(s_{t-N+1}+p_{t-N+1}^{*}\right), \pi_{t-1}, \ldots, \pi_{t-N}, z_{t} ; \phi, \gamma\right)$ is the ESTAR

function part used to obtain the main result, and $\Delta i i p_{t}$ is the first difference of logs of real industrial production multiplied by 100. The lag length $p$ is selected using the same method we use for selecting lags in the ESTAR part. The result is presented in Table 5. The time series path of ERPT is plotted in Figure 10. Overall, the performance of this extended ESTAR model is as good as that of the baseline ESTAR model.

\section{Conclusion}

In this paper, we show that the STAR models, a parsimonious parametric nonlinear time series model, offer a very convenient framework in examining the relationship between the ERPT and inflation. First, a simple theoretical model of ERPT determination suggests that the dynamics of ERPT can be well-approximated by a class of STAR models with inflation as a transition variable. Second, we can employ various U-shaped transition functions in the estimation of the time-varying ERPT. When this procedure is applied to U.S. import and domestic price data, we find the supporting 
evidence of nonlinearities in inflation dynamics. Our empirical results imply that the period of low ERPT is likely to be associated with the low inflation.

According to our model, the degree of ERPT varies over time because the fraction of importing firms opting out from the contract is endogenously determined by importing firms' optimization behavior. In the model, however, all imports are treated as if they are invoiced in the producer's (exporter's) currency. An alternative approach in introducing a time-varying ERPT is to use a model in which exporting firms endogenously choose between producer currency pricing (PCP) and local currency pricing (LCP). For example, a recent study by Gopinath, Itskhoki and Rigobon (2007) extends the model of Engel (2006) and investigates the role of the invoice currency in determining the observed ERPT. Our analysis do not consider this channel partly because we do not have data on individual exporters' invoice currency. Incorporating the effect of currency choice in our estimation procedure seems to be a promising direction for further analysis. 


\section{Appendix}

\section{A.1. Linearity test against the DLSTAR model}

Saikkonen and Luukkonen (1988) and Teräsvirta (1994) developed a methodology to test whether a series exhibits nonlinear behaviors described by STAR models. The test is based on a Taylor series approximation of the transition function of the STAR models.

Consider the following STAR model

$$
y_{t}=x_{t}^{\prime} \phi_{1}+G\left(z_{t} ; \gamma\right) x_{t}^{\prime} \phi_{2}
$$

where $x_{t}$ is a vector of explanatory variables. For the ESTAR model, Saikkonen and Luukkonen (1988) replace $G\left(z_{t} ; \gamma\right)=1-\exp \left\{-\gamma z_{t}^{2}\right\}$ by its third-order Taylor series approximation with respect to $\gamma$ evaluated at zero. This substitution yields the following auxiliary regression:

$$
y_{t}=x_{t}^{\prime} \beta_{1}+x_{t}^{\prime} z_{t} \beta_{2}+x_{t}^{\prime} z_{t}^{2} \beta_{3}+e_{t}
$$

Therefore, the linearity test against the ESTAR model is the same as testing the joint restriction that all nonlinear terms are zero: $\beta_{2}=\beta_{3}=0$. We refer to the LM test for this hypothesis as $L M_{1}$.

Reworking the case of the DLSTAR model is straightforward. We take a thirdorder Taylor series approximation of $G\left(z_{t} ; \gamma_{1}, \gamma_{2}, c\right)=\left(1+\exp \left\{-\gamma_{1}\left(z_{t}-c\right)\right\}\right)^{-1}+(1+$ $\left.\exp \left\{\gamma_{2}\left(z_{t}+c\right)\right\}\right)^{-1}$ with respect to $\gamma_{1}$ and $\gamma_{2}$ evaluated at $\gamma_{1}=\gamma_{2}=0$. Since the second derivative is zero, the derived expansion is $G\left(z_{t} ; \gamma_{1}, \gamma_{2}, c\right) \approx\left[\frac{\gamma_{1}}{4}\left(z_{t}-c\right)-\frac{\gamma_{1}^{3}}{48}\left(z_{t}-c\right)^{3}\right]+$ $\left[-\frac{\gamma_{2}}{4}\left(z_{t}+c\right)+\frac{\gamma_{2}^{3}}{48}\left(z_{t}+c\right)^{3}\right]$ and the substitution yields the following auxiliary regression:

$$
y_{t}=x_{t}^{\prime} \beta_{1}+x_{t}^{\prime} z_{t} \beta_{2}+x_{t}^{\prime} z_{t}^{2} \beta_{3}+x_{t}^{\prime} z_{t}^{3} \beta_{4}+e_{t}
$$

provided $\gamma_{1} \neq \gamma_{2}$. Here, the linearity test against the asymmetric DLSTAR model is identical to testing the joint restriction that all nonlinear terms are zero: $\beta_{2}=\beta_{3}=$ $\beta_{4}=0$. We refer to the LM test for this hypothesis as $L M_{3}$.

When we consider the symmetric case $\gamma=\gamma_{1}=\gamma_{2}$, the derived expansion has a simpler form $G\left(z_{t} ; \gamma, \gamma, c\right) \approx\left(\gamma^{3} c / 24-\gamma c / 2\right)+\left(\gamma^{3} c / 8\right) z_{t}^{2}$ and the substitution yields the following auxiliary regression: 


$$
y_{t}=x_{t}^{\prime} \beta_{1}+x_{t}^{\prime} z_{t}^{2} \beta_{3}+e_{t}
$$

The linearity test against the symmetric DLSTAR model is identical to the joint hypothesis that all nonlinear terms are zero: $\beta_{3}=0$. We refer to the LM test for this hypothesis as $L M_{2}$.

\section{A.2. Specification test among ESTAR, symmetric DLSTAR and asym- metric DLSTAR models}

Teräsvirta (1994) proposed a specification test of the LSTAR model with a single logistic transition function against the ESTAR model based on the auxiliary regression. Similarly, we can use the auxiliary regression equation for the asymmetric DLSTAR model $\left(\gamma_{1} \neq \gamma_{2}\right)$

$$
y_{t}=x_{t}^{\prime} \beta_{1}+x_{t}^{\prime} z_{t} \beta_{2}+x_{t}^{\prime} z_{t}^{2} \beta_{3}+x_{t}^{\prime} z_{t}^{3} \beta_{4}+e_{t},
$$

which nests that for the symmetric DLSTAR model $\left(\gamma_{1}=\gamma_{2}\right)$

$$
y_{t}=x_{t}^{\prime} \beta_{1}+x_{t}^{\prime} z_{t}^{2} \beta_{3}+e_{t}
$$

The test for the symmetric DLSTAR model against the asymmetric DLSTAR model is identical to testing the joint restriction $\beta_{2}=\beta_{4}=0$ in the auxiliary regression equation for the asymmetric DLSTAR. We refer to the LM test for this hypothesis as $\mathrm{LM}_{4}$.

Since the auxiliary regression equation for the ESTAR model is

$$
y_{t}=x_{t}^{\prime} \beta_{1}+x_{t}^{\prime} z_{t} \beta_{2}+x_{t}^{\prime} z_{t}^{2} \beta_{3}+e_{t}
$$

the test for the ESTAR model against the asymmetric DLSTAR model $\left(\gamma_{1} \neq \gamma_{2}\right)$ is identical to testing the joint restriction $\beta_{4}=0$ in the auxiliary regression equation for the asymmetric DLSTAR model. We refer to the LM test for this hypothesis as $L M_{5}$.

Finally, to test for the symmetric DLSTAR model $\left(\gamma_{1}=\gamma_{2}\right)$ against the ESTAR model, we test the joint restriction $\beta_{2}=0$ in the auxiliary regression equation for the ESTAR model. We refer to the LM test for this hypothesis as $L M_{6}$. 


\section{References}

[1] Ball, L., Mankiw, N. G., 1994. Asymmetric price adjustment and economic fluctuations. Economic Journal 104, 247-261.

[2] Ball, L., Mankiw, N. G., Romer, D., 1988. The New Keynesian economics and the output-inflation trade-off. Brookings Papers on Economic Activity 1, 1-65.

[3] Bec, F., Ben Salem, M., Carrasco, M., 2004. Detecting mean reversion in real exchange rates from a multiple regime STAR model. Mimeo.

[4] Calvo, G. A, 1983. Staggered prices in a utility-maximizing framework. Journal of Monetary Economics 12, 383-393.

[5] Calvo, G. A., Reinhart, C. M., 2002. Fear of floating. Quarterly Journal of Economics 117(2), 379-408.

[6] Campa, J. M., Goldberg, L. S., 2005. Exchange rate pass-through to domestic prices. Review of Economics and Statistics 87(4), 679-690.

[7] Choudhri, E. U., Hakura, D. S., 2006. Exchange rate pass-through to domestic prices: Does the inflationary environment matter? Journal of International Money and Finance 25(4), 614-639.

[8] Choudhri, E. U., Faruqee, H., Hakura, D. S., 2005. Explaining the exchange rate pass-through in different prices. Journal of International Economics 65(2), 349-374.

[9] Christiano, L. J., Eichenbaum, M., Evans, C.L., 2005. Nominal rigidities and the dynamic effects of a shock to monetary policy. Journal of Political Economy $113,1-45$.

[10] Devereux, M. B., Siu, H. E., 2007. State dependent pricing and business cycle asymmetries. International Economic Review 48(1), 281-310.

[11] Devereux, M. B., Yetman, J., 2002. Menu costs and the long-run output-inflation trade-off. Economics Letters, 76, 95-100.

[12] Devereux, M. B., Yetman, J., 2008. Price adjustment and exchange pass-through. Journal of International Money and Finance, forthcoming. 
[13] Engel, C., 2006. Equivalence results for optimal pass-through, optimal indexing to exchange rates, and optimal choice of currency for export pricing. Journal of the European Economic Association 4(6), 1249-1260.

[14] Goldberg, L. S., Campa, J. M., 2008. The sensitivity of the CPI to exchange rates: Distribution margins, imported inputs, and trade exposure. Review of Economics and Statistics, forthcoming.

[15] Goldberg, P.K., Knetter, M. M., 1997. Goods prices and exchange rates: What have we learned? Journal of Economic Literature 35, 1243-1272.

[16] Gopinath, G., Itskhoki, O., Rigobon, R., 2007. Currency choice and exchange rate pass-through. NBER Working Paper No. W13432.

[17] Granger, C. W. J., Teräsvirta, T., 1993. Modelling Nonlinear Economic Relationships. Oxford University Press, Oxford.

[18] Haggan, V., Ozaki, T., 1981. Modelling nonlinear random vibrations using an amplitude-dependent autoregressive time series model. Biometrika 68(2), 189196.

[19] Herzberg, V., Kapetanios, G., Price, S., 2003. Import prices and exchange rate pass-through: Theory and evidence from the United Kingdom. Bank of England Working Paper, No. 182.

[20] Kilian, L., Taylor, M. P., 2003. Why is it so difficult to beat the random walk forecast of exchange rates? Journal of International Economics 60, 85-107.

[21] McCarthy, J., 2007. Pass-through of exchange rates and import prices to domestic inflation in some industrialized economies. Eastern Economic Journal 33(4), 511-537.

[22] Michael, P., Nobay, A. R., Peel, D. A., 1997. Transaction costs and nonlinear adjustments in real exchange rates: An empirical investigation. Journal of Political Economy 105, 862-879.

[23] Otani, A., Shiratsuka, S., Shirota, T., 2003. The decline in the exchange rate pass-through: Evidence from Japanese import prices. Bank of Japan Monetary and Economic Studies 21(3), 53-81. 
[24] Romer, D., 1990, Staggered price setting with endogenous frequency of adjustment. Economics Letters 32, 205-210.

[25] Saikkonen, P., Luukkonen, R., 1988. Lagrange multiplier tests for testing nonlinearities in time series models. Scandinavian Journal of Statistics 15(1) 55-68.

[26] Sekine, T., 2006. Time-varying exchange rate pass-through: Experiences of some industrial countries. BIS Working Paper, No. 202.

[27] Taylor, J. B., 1980. Aggregate dynamics and staggered contracts. Journal of Political Economy 88, 1-23.

[28] Taylor, J. B., 2000. Low inflation, pass-through, and the pricing power of firms. European Economic Review 44, 1389-1408.

[29] Taylor, M. P., Peel, D. A., 2000. Nonlinear adjustment, long-run equilibrium and exchange rate fundamentals. Journal of International Money and Finance $19,33-53$.

[30] Taylor, M. P., Peel, D. A., Sarno, L., 2001. Nonlinear mean-reversion in real exchange rates: Toward a solution to the purchasing power parity puzzles. International Economic Review 42, 1015-1042.

[31] Teräsvirta, T., 1994. Specification, estimation, and evaluation of smooth transition autoregressive models. Journal of the American Statistical Association 89, $208-.218$.

[32] van Dijk, D., Teräsvirta, T., Franses, P., 2002. Smooth transition autoregressive models: A survey of recent developments. Econometrics Reviews 21, 1-47.

[33] Walsh, C. E., 2003. Monetary Theory and Policy. Second Edition. MIT Press, Cambridge. 
Table 1. LM-type tests for STAR nonlinearity

\begin{tabular}{|c|c|c|c|c|c|c|c|}
\hline & & \multicolumn{6}{|c|}{ Transition Variable $\left(z_{t}=d^{-1} \sum_{j=1}^{d} \pi_{t-j}\right)$} \\
\hline $\mathrm{H}_{0}$ vs. $\mathrm{H}_{1}$ & Test Statistics & $d=1$ & $d=2$ & $d=3$ & $d=4$ & $d=5$ & $d=6$ \\
\hline \multirow[t]{4}{*}{ Linear vs. ESTAR } & $L M_{1}$ & 4.93 & 4.12 & 3.89 & 3.58 & 3.03 & 2.36 \\
\hline & & $(0.00)$ & $(0.00)$ & $(0.00)$ & $(0.00)$ & $(0.00)$ & $(0.00)$ \\
\hline & $L M_{1}^{*}$ & 347.1 & 341.1 & 341.5 & 344.6 & 346.9 & 344.9 \\
\hline & & $(0.00)$ & $(0.00)$ & $(0.00)$ & $(0.00)$ & $(0.00)$ & $(0.00)$ \\
\hline \multirow[t]{2}{*}{ Linear vs. } & $L M_{2}$ & 4.86 & 3.07 & 4.01 & 3.20 & 3.23 & 3.14 \\
\hline & & $(0.00)$ & $(0.00)$ & $(0.00)$ & $(0.00)$ & $(0.00)$ & $(0.00)$ \\
\hline \multirow[t]{2}{*}{ symmetric DLSTAR } & $L M_{2}^{*}$ & 372.9 & 377.2 & 370.8 & 371.8 & 373.1 & 369.4 \\
\hline & & $(0.00)$ & $(0.00)$ & $(0.00)$ & $(0.00)$ & $(0.00)$ & $(0.00)$ \\
\hline \multirow[t]{2}{*}{ Linear vs. } & $L M_{3}$ & 5.14 & 4.04 & 3.57 & 2.95 & 2.68 & 1.98 \\
\hline & & $(0.00)$ & $(0.00)$ & $(0.00)$ & $(0.00)$ & $(0.00)$ & $(0.00)$ \\
\hline \multirow[t]{2}{*}{ asymmetric DLSTAR } & $L M_{3}^{*}$ & 351.8 & 355.3 & 354.1 & 357.7 & 358.2 & 358.4 \\
\hline & & $(0.00)$ & $(0.00)$ & $(0.00)$ & $(0.00)$ & $(0.00)$ & $(0.00)$ \\
\hline
\end{tabular}

Notes: Lag length is $N=6$. LM test statistics for linearity against the ESTAR model, the symmetric DLSTAR model, and the asymmetric DLSTAR model are denoted as $L M_{1}$, $L M_{2}$, and $L M_{3}$, respectively. The heteroskedasticity-robust variants of the $L M_{1}, L M_{2}$, and $L M_{3}$ are denoted as $L M_{1}^{*}, L M_{2}^{*}$, and $L M_{3}^{*}$, respectively (see Granger and Teräsvirta, 1993). Numbers in parentheses below LM statistics are $p$-values. 
Table 2. ERPT regression results: baseline case

A: ESTAR model $(d=3)$

$$
\begin{aligned}
& \pi_{t}= \underset{(3.118)}{0.099}+\underset{(2.322)}{0.123 \pi_{t-1}}+\underset{(4.706)}{0.200} \pi_{t-3}-\underset{(1.689)}{0.081-4} \pi_{t-4}+\underset{(9.746)}{0.336} \Delta\left(s_{t}+p_{t}^{*}\right) \\
&+\underset{(2.803)}{0.093 \Delta}\left(s_{t-1}+p_{t-1}^{*}\right)+\underset{(1.859)}{0.074 \Delta}\left(s_{t-4}+p_{t-4}^{*}\right)+\underset{(1.349)}{0.039} \Delta\left(s_{t-5}+p_{t-5}^{*}\right) \\
&+ \underset{(2.103)}{[0.752}-\underset{(3.400)}{0.352} \pi_{t-5}+\underset{(19.246)}{0.664} \Delta\left(s_{t}+p_{t}^{*}\right)-\underset{(2.849)}{0.569 \Delta}\left(s_{t-2}+p_{t-2}^{*}\right) \\
&\left.-\underset{(1.393)}{0.300} \Delta\left(s_{t-4}+p_{t-4}^{*}\right)\right] G\left(z_{t} ; \widehat{\gamma}\right)+\widehat{\varepsilon}_{t}, \\
& G\left(z_{t} ; \widehat{\gamma}\right)=1-\exp \left\{\underset{(4.777)}{-0.076}\left(\frac{1}{3} \sum_{j=1}^{3} \pi_{t-j}\right)^{2} / 0.477^{2}\right\}
\end{aligned}
$$$$
R^{2}=0.606, \text { se }=0.476, \text { obs }=396, \operatorname{LM}(1)=[0.146], \operatorname{LM}(1-12)=[0.189]
$$

B: Symmetric DLSTAR model $(d=1)$

$$
\begin{aligned}
& \pi_{t}=\underset{(3.466)}{0.098}+\underset{(3.866)}{0.208} \pi_{t-1}+\underset{(4.278)}{0.159} \pi_{t-3}-\underset{(2.195)}{0.101} \pi_{t-5}+\underset{(12.519)}{0.349} \Delta\left(s_{t}+p_{t}^{*}\right) \\
& +\underset{(2.341)}{0.075 \Delta}\left(s_{t-1}+p_{t-1}^{*}\right)-\underset{(2.441)}{0.070 \Delta} \Delta\left(s_{t-2}+p_{t-2}^{*}\right)+\underset{(2.081)}{0.066 \Delta}\left(s_{t-5}+p_{t-5}^{*}\right) \\
& +\left[\begin{array}{l}
0.242 \pi \\
(1.150)
\end{array} \pi_{t-4}-\underset{(2.749)}{0.739} \pi_{t-5}+\underset{(5.269)}{1.230} \pi_{t-6}+\underset{(23.333)}{0.651} \Delta\left(s_{t}+p_{t}^{*}\right)\right. \\
& \underset{(5.568)}{0.438} \Delta\left(s_{t-1}+p_{t-1}^{*}\right)+\underset{(3.109)}{0.350} \Delta\left(s_{t-2}+p_{t-2}^{*}\right) \underset{(2.695)}{0.534 \Delta}\left(s_{t-4}+p_{t-4}^{*}\right) \\
& \left.\underset{(1.957)}{0.356 \Delta} \Delta\left(s_{t-5}+p_{t-5}^{*}\right)\right] G\left(z_{t} ; \widehat{\gamma}, \widehat{c}\right)+\widehat{\varepsilon}_{t}, \\
& G\left(z_{t} ; \widehat{\gamma}, \widehat{c}\right)=\left(1+\exp \left\{\underset{(2.924)}{-5.130}\left(\pi_{t-1}-\underset{(21.283)}{1.474}\right) / 0.686\right\}\right)^{-1} \\
& +\left(1+\exp \left\{\begin{array}{l}
5.130 \\
(2.924)
\end{array}\left(\pi_{t-1}+\underset{(21.283)}{1.474}\right) / 0.686\right\}\right)^{-1} \\
& R^{2}=0.654, \text { se }=0.448, \text { obs }=396, \operatorname{LM}(1)=[0.040], \operatorname{LM}(1-12)=[0.242]
\end{aligned}
$$

Notes: Numbers in parentheses below coefficient estimates are $t$-statistics in absolute values. $R^{2}$ denotes the coefficient of determination and se is the standard error of the regression. Numbers in brackets for $L M(1)$ and $L M(1-12)$ are $p$-values for Lagrange multiplier test statistics for first-order, and up to twelfth-order serial correlations in the residuals, respectively. 
Table 3. ERPT regression results: asymmetric adjustment

Asymmetric DLSTAR model $(d=1)$

$$
\begin{aligned}
& \pi_{t}=\underset{(3.349)}{0.095}+\underset{(4.183)}{0.270} \pi_{t-1}+\underset{(4.094)}{0.153 \pi} \pi_{t-3}-\underset{(2.326)}{0.105} \pi_{t-5}+\underset{(12.352)}{0.341} \Delta\left(s_{t}+p_{t}^{*}\right) \\
& +\underset{(1.879)}{0.062 \Delta} \Delta\left(s_{t-1}+p_{t-1}^{*}\right)-\underset{(2.747)}{0.078} \Delta\left(s_{t-2}+p_{t-2}^{*}\right)+\underset{(2.071)}{0.064 \Delta}\left(s_{t-5}+p_{t-5}^{*}\right) \\
& +\left[-\underset{(1.722)}{0.198} \pi_{t-1}-\underset{(1.979)}{0.510} \pi_{t-5}+\underset{(4.666)}{1.001} \pi_{t-6}+\underset{(23.868)}{0.659} \Delta\left(s_{t}+p_{t}^{*}\right)\right. \\
& \underset{(3.324)}{0.338 \Delta}\left(s_{t-1}+p_{t-1}^{*}\right)+\underset{(3.352)}{0.417} \Delta\left(s_{t-2}+p_{t-2}^{*}\right) \underset{(2.685)}{0.298 \Delta}\left(s_{t-4}+p_{t-4}^{*}\right) \\
& \left.\underset{(2.699)}{0.482 \Delta} \Delta\left(s_{t-5}+p_{t-5}^{*}\right)\right] G\left(z_{t} ; \widehat{\gamma}_{1}, \widehat{\gamma}_{2}, \widehat{c}_{1}, \widehat{c}_{2}\right)+\widehat{\varepsilon}_{t} \\
& G\left(z_{t} ; \widehat{\gamma}_{1}, \widehat{\gamma}_{2}, \widehat{c}_{1}, \widehat{c}_{2}\right)=\left(1+\exp \left\{\underset{(1.129)}{-5.762}\left(\pi_{t-1}-\underset{(14.924)}{1.591}\right) / 0.686\right\}\right)^{-1} \\
& +\left(1+\exp \left\{\underset{(1.124)}{55.253}\left(\pi_{t-1}+\underset{(156.218)}{1.293}\right) / 0.686\right\}\right)^{-1} \\
& R^{2}=0.663, \text { se }=0.443, \text { obs }=396, \operatorname{LM}(1)=[0.073], \operatorname{LM}(1-12)=[0.247]
\end{aligned}
$$

Notes: See notes of Table 2. 
Table 4. LM-type tests for STAR model selection

\begin{tabular}{|c|c|c|c|c|c|c|c|}
\hline & & \multicolumn{6}{|c|}{ Transition Variable $\left(z_{t}=d^{-1} \sum_{j=1}^{d} \pi_{t-j}\right)$} \\
\hline $\mathrm{H}_{0}$ vs. $\mathrm{H}_{1}$ & Test Statistics & $d=1$ & $d=2$ & $d=3$ & $d=4$ & $d=5$ & $d=6$ \\
\hline \multirow[t]{2}{*}{ Symmetric DLSTAR } & $L M_{4}$ & 3.86 & 3.42 & 2.84 & 2.47 & 2.17 & 1.26 \\
\hline & & $(0.00)$ & $(0.00)$ & $(0.00)$ & $(0.00)$ & $(0.01)$ & $(0.19)$ \\
\hline \multirow[t]{2}{*}{ vs. Asymmetric DLSTAR } & $L M_{4}^{*}$ & 358.2 & 348.6 & 350.9 & 356.2 & 360.3 & 361.3 \\
\hline & & $(0.00)$ & $(0.00)$ & $(0.00)$ & $(0.00)$ & $(0.00)$ & $(0.00)$ \\
\hline \multirow[t]{2}{*}{ ESTAR } & $L M_{5}$ & 4.41 & 3.24 & 2.52 & 1.56 & 1.81 & 1.19 \\
\hline & & $(0.00)$ & $(0.00)$ & $(0.01)$ & $(0.10)$ & $(0.05)$ & $(0.29)$ \\
\hline \multirow[t]{2}{*}{ vs. Asymmetric DLSTAR } & $L M_{5}^{*}$ & 374.1 & 376.1 & 371.3 & 371.8 & 372.4 & 369.2 \\
\hline & & $(0.00)$ & $(0.00)$ & $(0.00)$ & $(0.00)$ & $(0.00)$ & $(0.00)$ \\
\hline \multirow[t]{2}{*}{ Symmetric DLSTAR } & $L M_{6}$ & 2.97 & 3.34 & 3.02 & 3.30 & 2.47 & 1.32 \\
\hline & & $(0.00)$ & $(0.00)$ & $(0.00)$ & $(0.00)$ & $(0.01)$ & $(0.20)$ \\
\hline \multirow[t]{2}{*}{ vs. ESTAR } & $L M_{6}^{*}$ & 377.0 & 377.0 & 373.6 & 373.1 & 372.6 & 369.8 \\
\hline & & $(0.00)$ & $(0.00)$ & $(0.00)$ & $(0.00)$ & $(0.00)$ & $(0.00)$ \\
\hline
\end{tabular}

Notes: Lag length is $N=6 . L M_{4}$ is the LM test statistic for the null hypothesis of the symmetric DLSTAR model against the asymmetric DLSTAR model. $L M_{5}$ is the LM test statistic for the null hypothesis of the ESTAR model against the asymmetric DLSTAR model. $L M_{6}$ is the LM test statistic for the null hypothesis of the symmetric DLSTAR model against the ESTAR model. The heteroskedasticity-robust variants of the $L M_{4}, L M_{5}$, and $L M_{6}$ are denoted as $L M_{4}^{*}, L M_{5}^{*}$, and $L M_{6}^{*}$, respectively. Numbers in parentheses below LM statistics are $p$-values. 
Table 5. ERPT regression results: demand shocks

ESTAR model $(d=1)$

$$
\begin{aligned}
& \pi_{t}=\underset{(4.382)}{0.102}+\underset{(5.041)}{0.279} \pi_{t-1}+\underset{(5.348)}{0.155} \pi_{t-3}-\underset{(2.440)}{0.099} \pi_{t-4}-\underset{(3.469)}{0.119} \pi_{t-5}-\underset{(1.834)}{0.063} \pi_{t-6} \\
& +\underset{(12.792)}{0.329} \Delta\left(s_{t}+p_{t}^{*}\right)+\underset{(3.218)}{0.091 \Delta}\left(s_{t-1}+p_{t-1}^{*}\right)-\underset{(3.154)}{0.078 \Delta}\left(s_{t-2}+p_{t-2}^{*}\right)+\underset{(1.765)}{0.051} \Delta\left(s_{t-4}+p_{t-4}^{*}\right) \\
& +\underset{(4.054)}{0.105} \Delta\left(s_{t-5}+p_{t-5}^{*}\right)-\underset{(3.173)}{0.096} \Delta i i p_{t}+\underset{(2.569)}{0.075 \Delta i i p_{t-1}}-\underset{(2.354)}{0.072 \Delta i i p_{t-4}} \\
& +\left[\begin{array}{l}
0.461 \\
(2.741)
\end{array} \underset{(3.091)}{0.472} \pi_{t-1}-\underset{(2.924)}{0.604} \pi_{t-2}+\underset{(2.071)}{0.631} \pi_{t-4}+\underset{(3.124)}{0.767} \pi_{t-6}+\underset{(26.089)}{0.671} \Delta\left(s_{t}+p_{t}^{*}\right)\right. \\
& \underset{(2.499)}{-0.332 \Delta}\left(s_{t-1}+p_{t-1}^{*}\right)+\underset{(2.881)}{0.535 \Delta} \Delta\left(s_{t-2}+p_{t-2}^{*}\right) \underset{(2.701)}{0.670 \Delta}\left(s_{t-4}+p_{t-4}^{*}\right) \\
& \left.\underset{(4.568)}{0.545 \Delta}\left(s_{t-5}+p_{t-5}^{*}\right)+\underset{(2.552)}{0.513 \Delta i i p_{t}}-\underset{(4.202)}{0.459} \Delta i i p_{t-1}+\underset{(3.302)}{0.777} \Delta i i p_{t-4}\right] G\left(z_{t} ; \widehat{\gamma}\right)+\widehat{\varepsilon}_{t}, \\
& G\left(z_{t} ; \widehat{\gamma}\right)=1-\exp \left\{\begin{array}{l}
-0.079 \pi_{t-1}^{2} / 0.686^{2} \\
(4.499)
\end{array}\right\} \\
& R^{2}=0.652, \text { se }=0.456, \text { obs }=396, \operatorname{LM}(1)=[0.021], \operatorname{LM}(1-12)=[0.105]
\end{aligned}
$$

Notes: See notes of Table 2. 
Figure 1. ERPT and inflation: Two-period contract case $(N=2)$

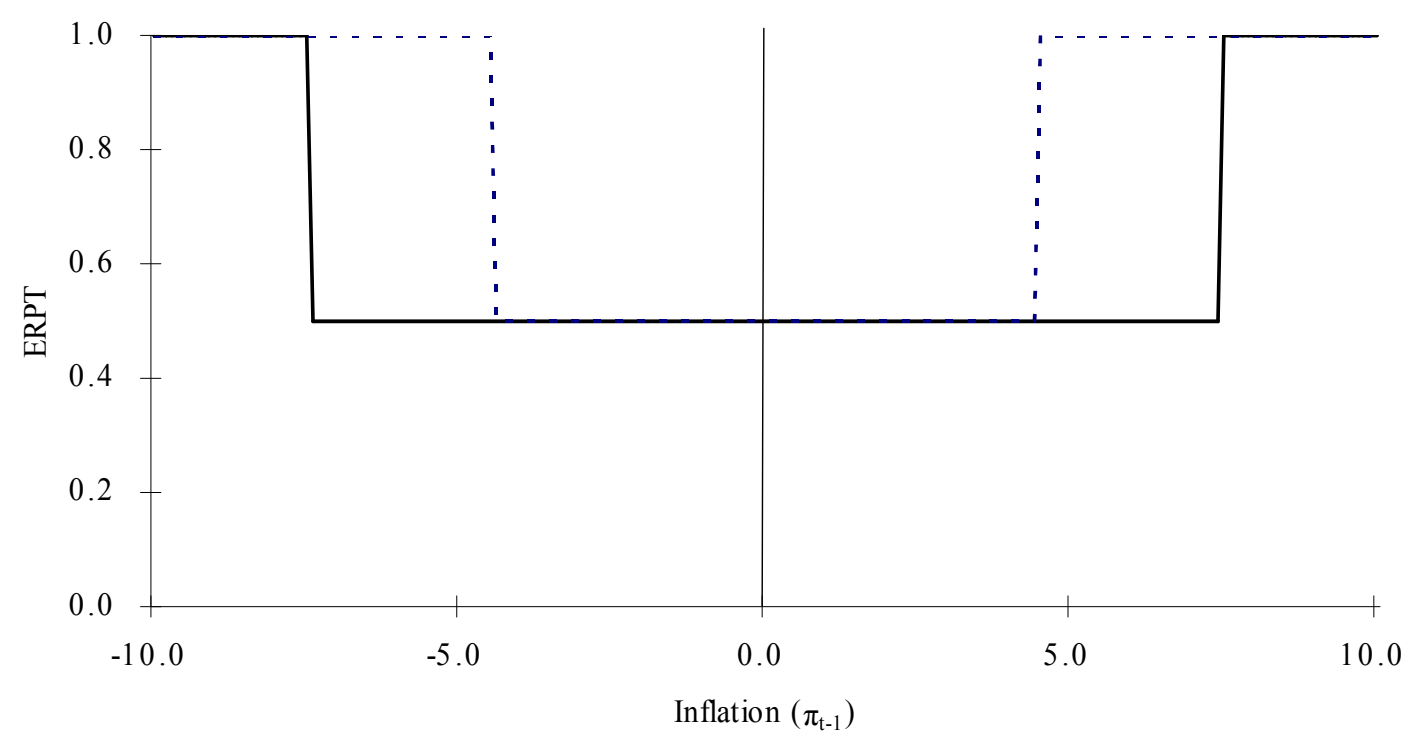

Notes: Solid line: $F=155$ and $\sigma^{2}=100$. Dotted line: $F=120$ and $\sigma^{2}=100$.

Figure 2. ERPT and inflation: Three-period contract case $(N=3)$

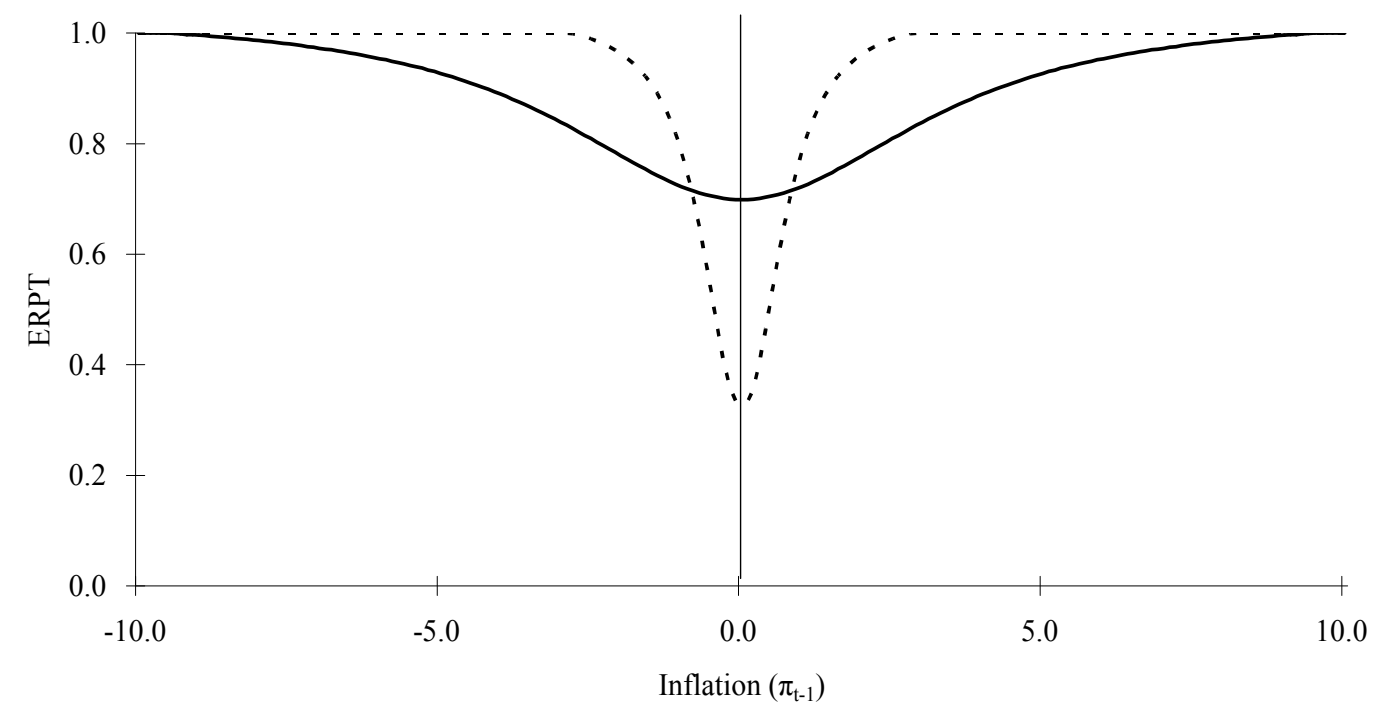

Notes: Solid line: $F=260$ and $\sigma^{2}=170$. Dotted line: $F=20$ and $\sigma^{2}=12$. 
Figure 3. Producer price index inflation

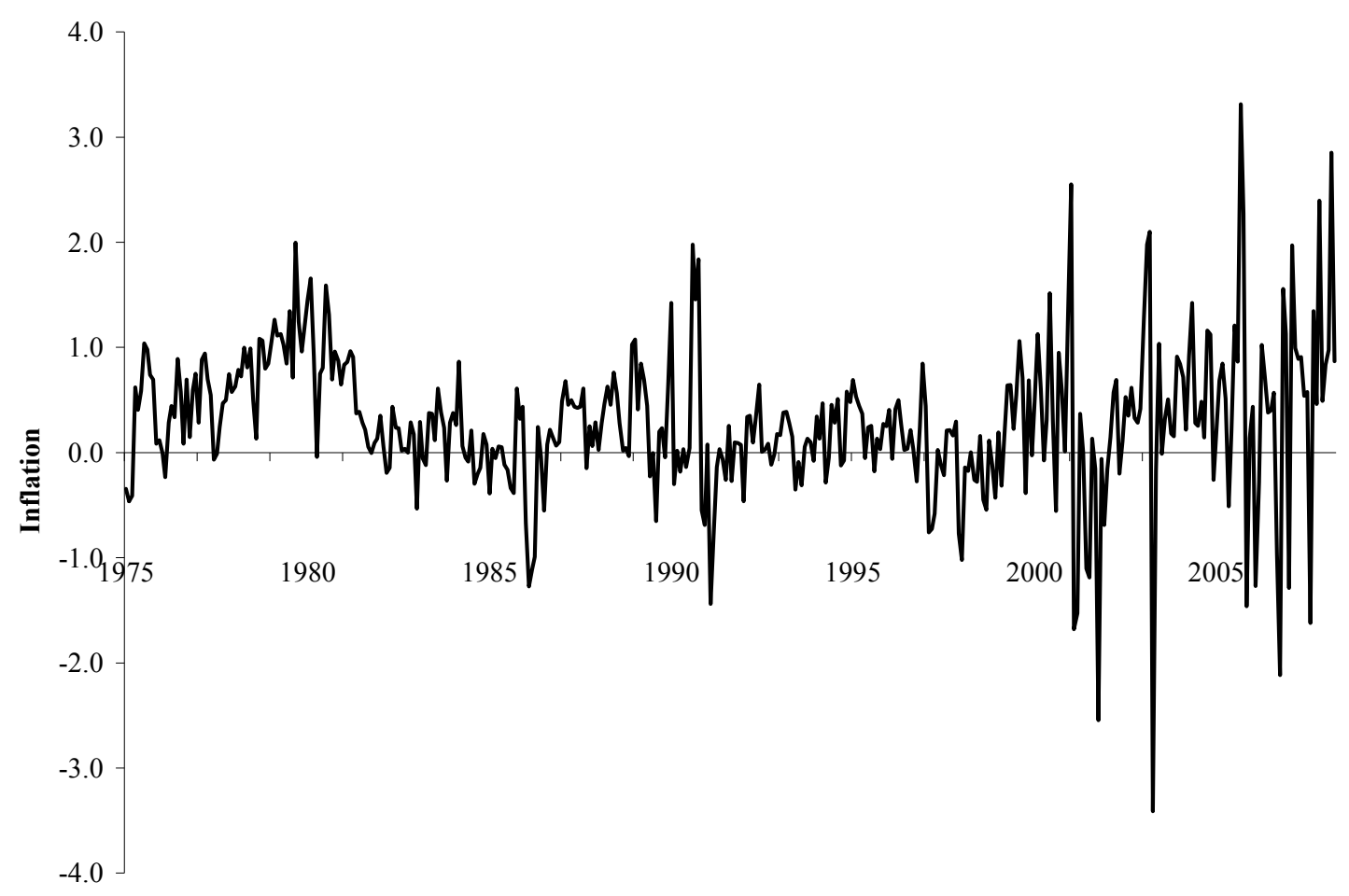

Note: Seasonally adjusted series. 
Figure 4. ERPT against transition variable: ESTAR model

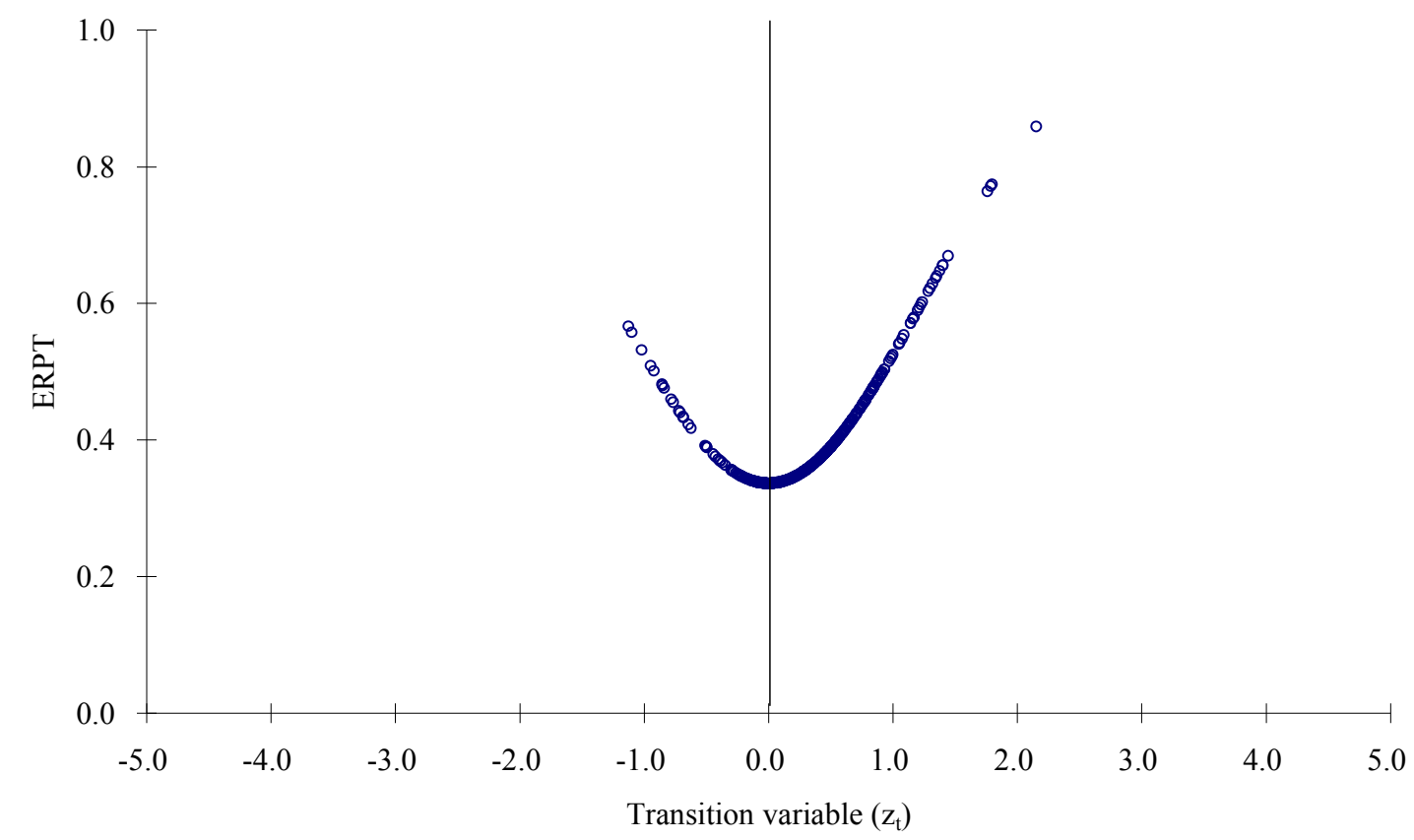

Figure 5. ERPT over time: ESTAR model

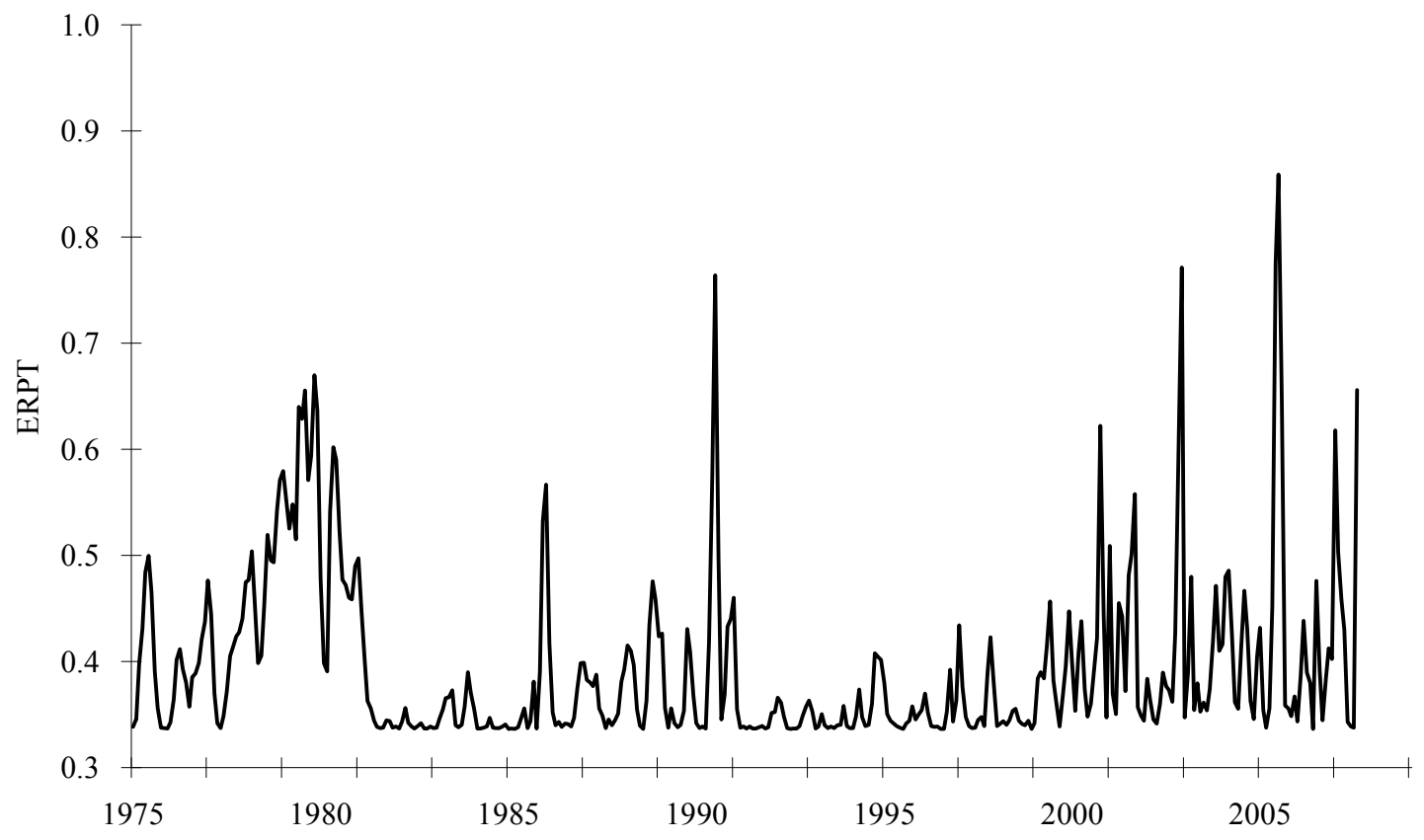


Figure 6. ERPT against transition variable: Symmetric DLSTAR model

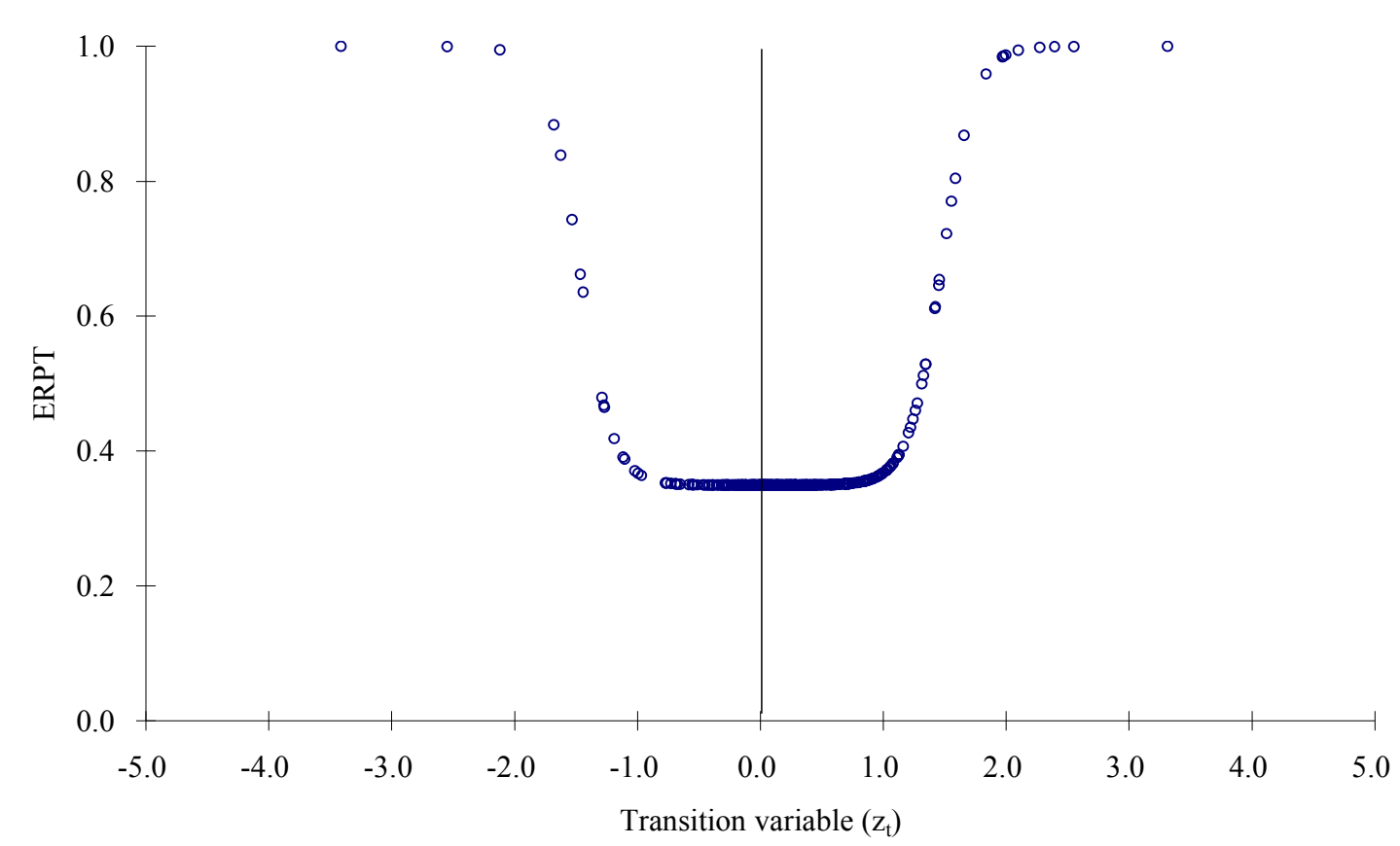

Figure 7. ERPT over time: Symmetric DLSTAR model

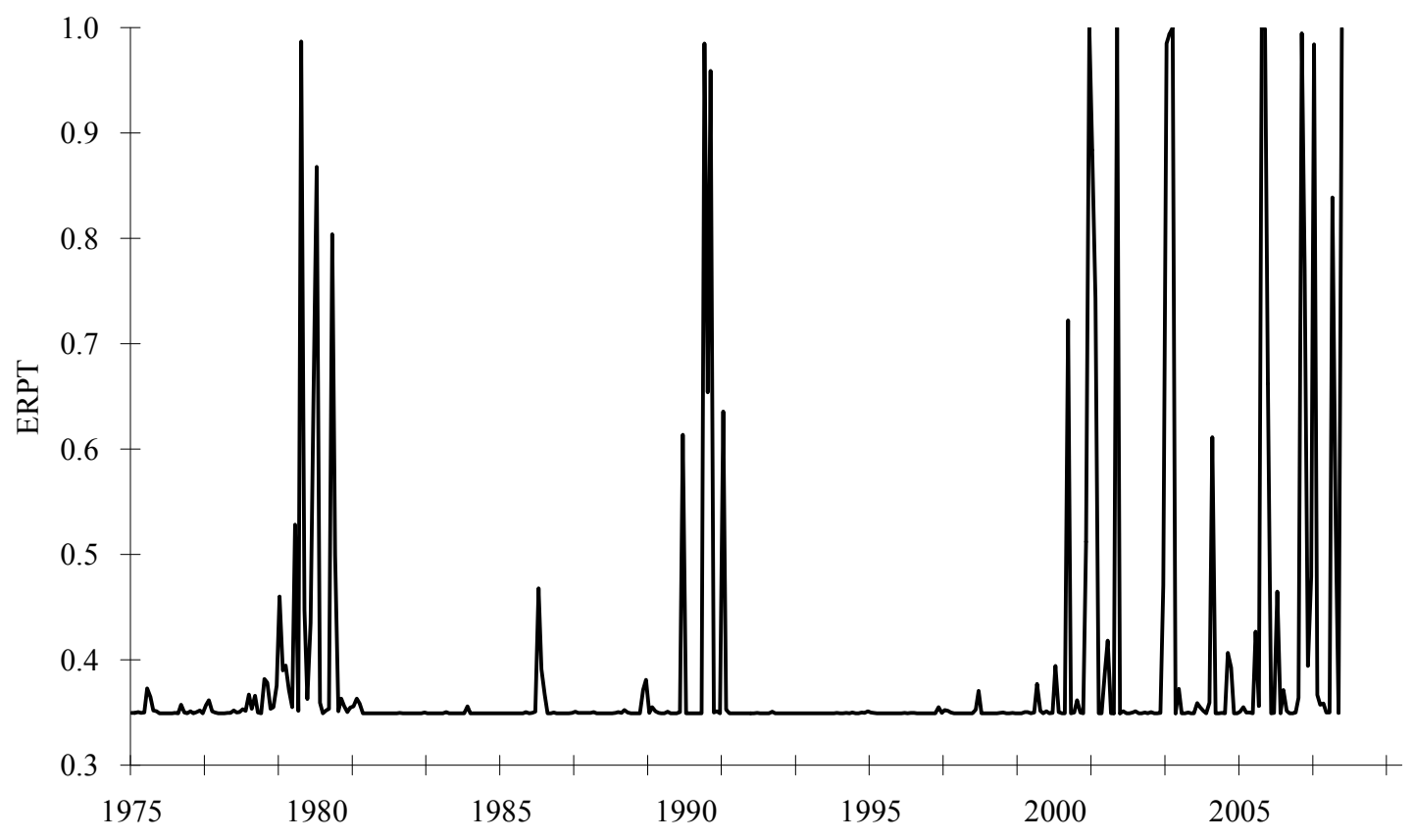


Figure 8. ERPT against transition variable: Asymmetric DLSTAR model

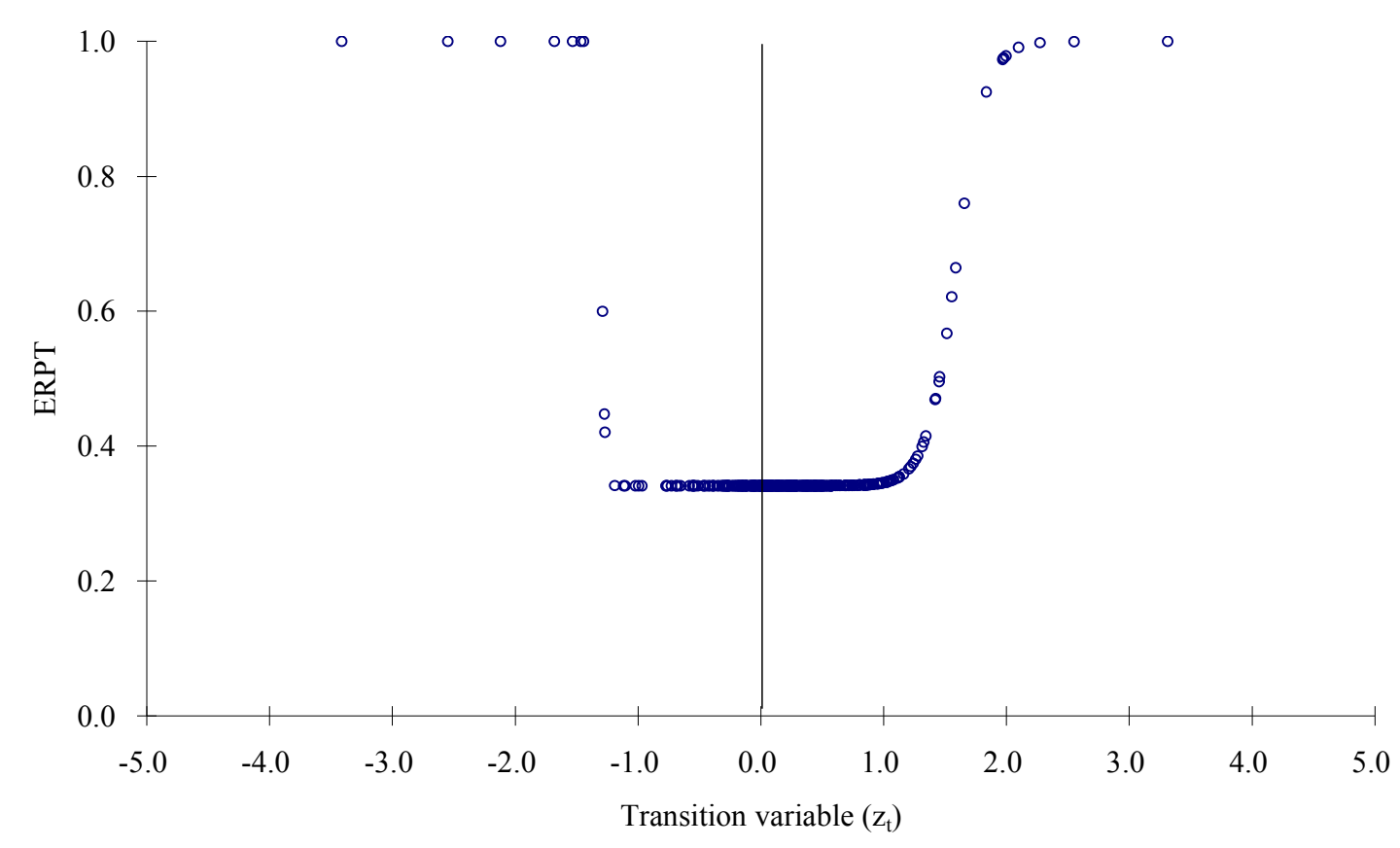

Figure 9. ERPT over time: Asymmetric DLSTAR model

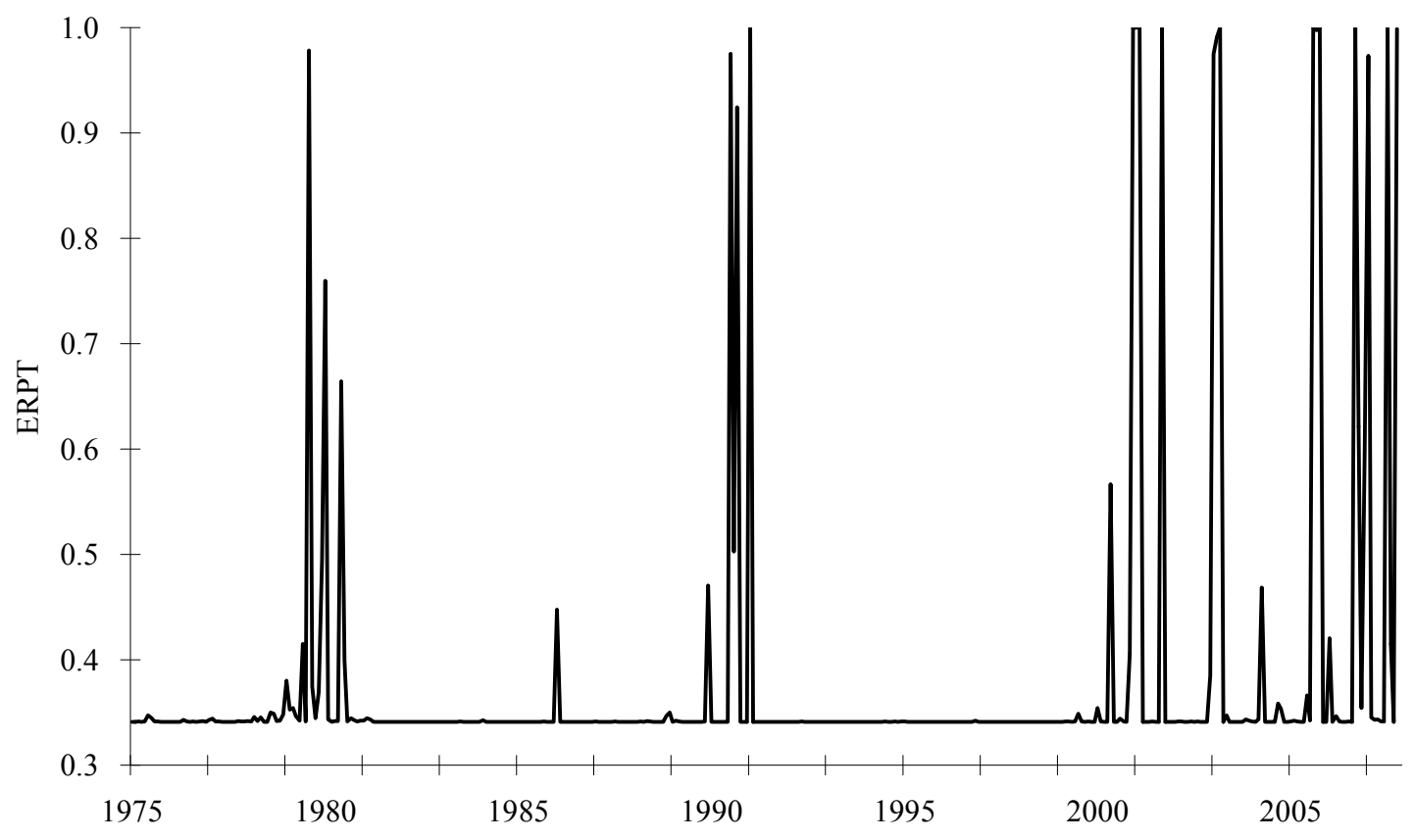


Figure 10. ERPT over time: ESTAR model and demand shocks

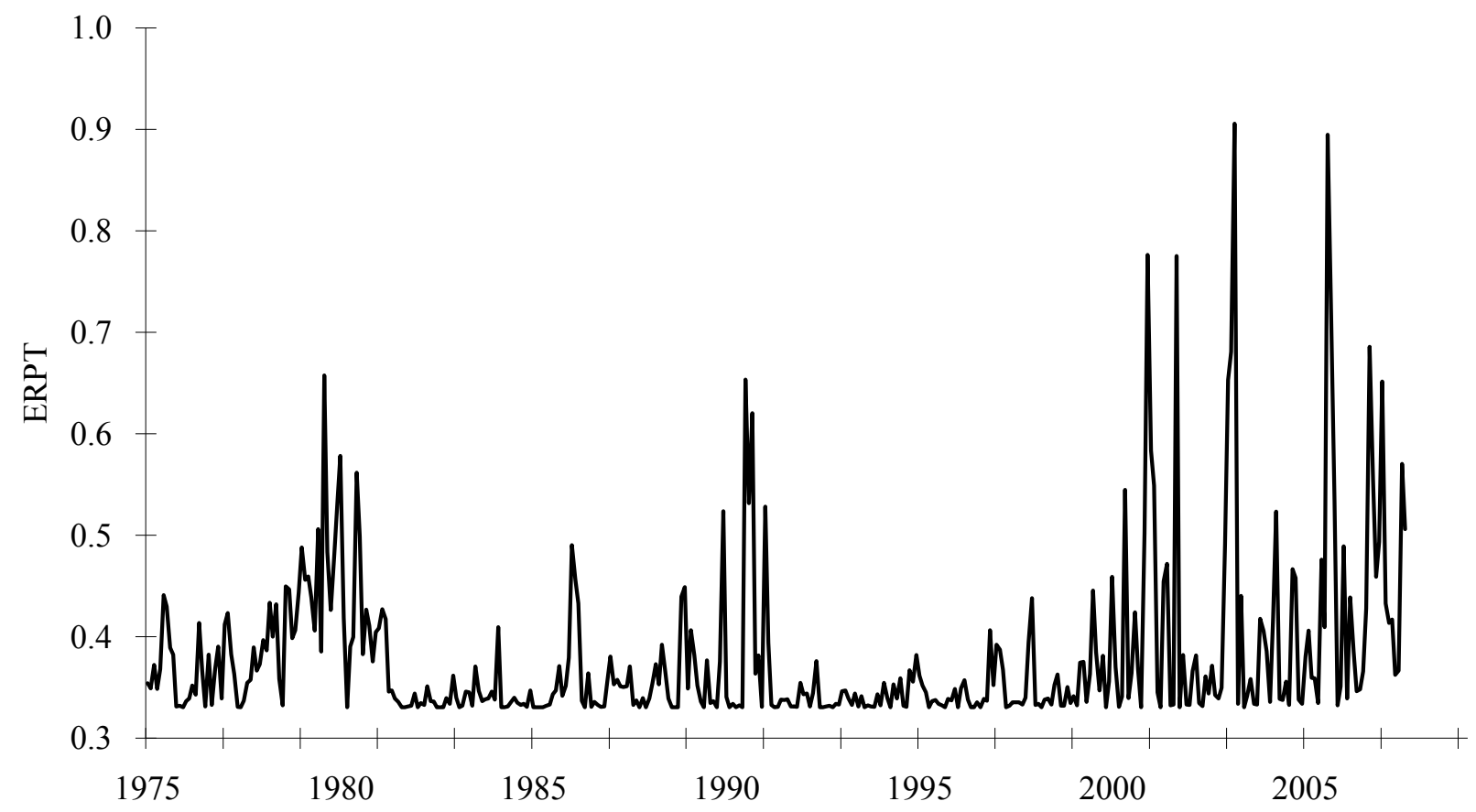

